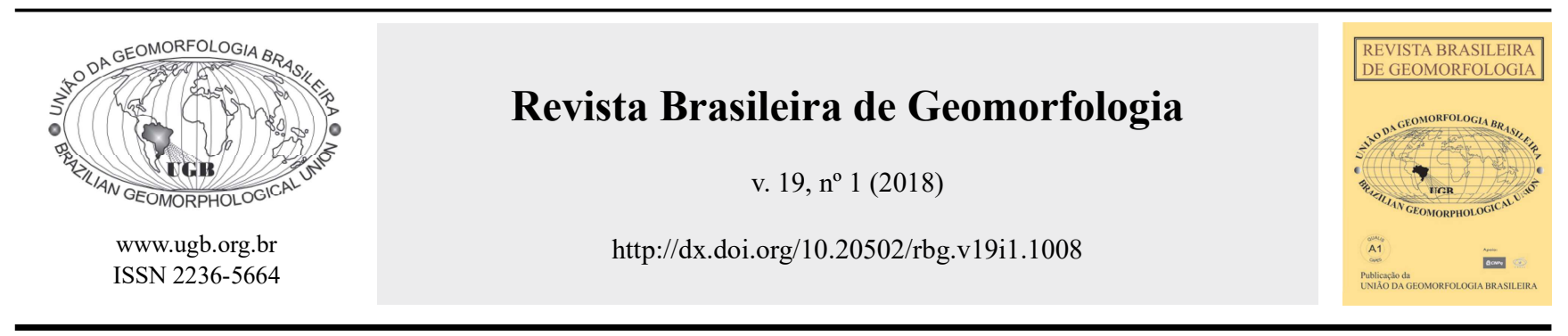

\title{
CARACTERIZAÇÃO GEOMORFOLÓGICA DO RELEVO SUBMARINO DE ÁREAS MARINHAS PROTEGIDAS BRASILEIRAS COM BASE EM TÉCNICAS DE ANÁLISE ESPACIAL
}

\author{
GEOMORPHOLOGICAL CHARACTERIZATION OF BRAZILIAN \\ MARINE PROTECTED AREAS SUBMARINE RELIEF OF BASED ON \\ SPATIAL ANALYSIS TECHNIQUES
}

\author{
Mario Luiz Martins Pereira \\ Instituto Chico Mendes de Conservação da Biodiversidade, Ministério do Meio Ambiente \\ Rodovia Mauricio S. Sobrinho, Km 01, Florianópolis, Santa Catarina. CEP 88053-700. Brasil
}

Email: marioluizmartinspereira@gmail.com

\begin{abstract}
Jarbas Bonetti
Laboratório de Oceanografia Costeira, Universidade Federal de Santa Catarina

Estação Experimental "Prof. Elpídio Beltrame”, Florianópolis, Santa Catarina. CEP 88061-600. Brasil

Email: jarbas.bonetti@ufsc.br
\end{abstract}

\begin{tabular}{l} 
Informações sobre o Artigo \\
\hline Recebido (Received): \\
03/02/2016 \\
Aceito (Accepted): \\
07/03/2017
\end{tabular}

Palavras-chave:

Unidades de Conservação Marinhas; Geodiversidade; Benthic Terrain Modeler (BTM).

\section{Keywords:}

Marine Protected Areas;

Geodiversity; Benthic Terrain Modeler (BTM).

\section{Resumo:}

O substrato marinho possui grande importância na atração e na agregação de vida, sendo o estabelecimento de habitats bênticos condicionado primariamente por suas características morfossedimentares. Este trabalho analisa o fundo marinho raso de três importantes Unidades de Conservação Marinho Costeiras do Brasil através dos estudos morfológicos das feições de relevo e das paleodrenagens e paleobacias hidrográficas que foram estabelecidas em condições pretéritas de exposição subaérea da plataforma continental. Os resultados, obtidos através de técnicas de análise espacial em Sistemas de Informações Geográficas (SIG), trazem informações inéditas sobre o relevo de fundo dessas áreas, como sua complexidade morfológica, que poderão ser usadas no manejo e na conservação dos recursos naturais marinhos brasileiros, seja por sua geodiversidade ou pela biodiversidade associada a essas feições.

\begin{abstract}
:
The marine substrate has high importance in attracting and aggregating life, being the establishment of benthic habitats primarily conditioned by its morphosedimentary features. This paper analyses the shallow seabed of three important Marine Protected Areas in Brazil through morphological studies of their actual bottom features, paleo drainages and paleo watersheds that were established in past conditions of subaerial exposure of the inner continental shelf. The results obtained through spatial analysis techniques in Geographic Information Systems
\end{abstract}


(GIS) bring new information about the submerged relief in these areas, as well as its morphological complexity, which can be applied in the management and conservation of Brazilian marine natural resources, taking into account local geodiversity as well as the biodiversity associated with the recognized features.

\section{Introdução}

O fundo marinho possui grande importância na atração e na agregação de vida, sendo o estabelecimento de habitats bênticos condicionado primariamente por suas características morfossedimentares. Apesar disso, tal compartimento ainda é relativamente pouco estudado, seja de forma sistemática, seja em escala de detalhe (LUNDBLAD, 2004). Tal carência, particularmente importante no Brasil, se reflete nas estratégias de criação e gestão das Unidades de Conservação (UCs) nacionais, tanto nas metodologias usadas para a definição dos limites das áreas protegidas (IBAMA, 2002) quanto na dificuldade de acesso a dados dessa natureza, importantes para as tomadas de decisão. Em outros países, exemplos de uso efetivo de dados relativos à camada de fundo no planejamento de UCs e manejo de recursos naturais são cada vez mais frequentes (IAMPIETRO; KVITEK; MORRIS, 2005; LUNDBLAD et al., 2006). Estes são derivados de pesquisas associadas a diferentes áreas das ciências naturais e da conservação, sendo utilizadas abordagens variadas na caracterização da camada de fundo (LUNDBLAD, 2004; RINEHART et al., 2004).

Do ponto de vista ecológico, o tipo de substrato pode ser considerado um dos principais fatores que condicionam o estabelecimento de vida no leito marinho, sendo a profundidade igualmente um aspecto chave na instauração da comunidade biológica. Outras características do assoalho marinho como a morfologia, por exemplo, também podem orientar a diversidade e abundância de vida local (HARRIS, 2012; KENDALL; BAUER; JEFFREY, 2009; KENDALL; MILLER; PITTMAN, 2011; KRACKER; KENDALL; MCFALL, 2008). Nessa linha, surge o conceito de Paisagem Marinha, ou Seascape (BOSTRÖM et al., 2011; ROFF; TAYLOR, 2000; WEDDING et al., 2011), como uma categoria de análise que busca, através de mapeamento em diferentes escalas espaciais, descrever o ambiente marinho de acordo com suas principais características geofísicas. O conceito pode englobar tanto aspectos do assoalho marinho quanto da coluna d'água, permitindo que se estabeleça uma visão mais global e integrada sobre a área analisada (CONNOR et al., 2006)
As aplicações do conceito de Paisagem Marinha disponíveis na literatura tiveram por base mapas históricos de batimetria e sedimentologia, complementados por dados físico-químicos e hidrodinâmicos obtidos em campo, a partir de modelos numéricos ou, ainda, derivados de imagens de satélite, entre outras camadas temáticas ou de referência (ALHAMDANI et al., 2007; BUHL-MORTENSEN; DOLAN; BUHL-MORTENSEN, 2009; HAMDI; POPULUS; PIEL, 2007; MAROTTA; AGUZZI, 2009). As chaves de classificação propostas por estes autores são flexíveis de acordo com os ambientes e suas respectivas fisiografias, devendo ser adaptadas conforme as necessidades específicas de gestão de cada local (HAMDI; POPULUS; PIEL, 2007). A compartimentação da morfologia de fundo em feições caracterizadas numericamente, gerando zonas e estruturas morfológicas de fundo, é um exemplo de avanço metodológico de grande aceitação, sendo utilizada em diferentes frentes de conservação e uso de recursos naturais (IAMPIETRO; YOUNG; KVITEK, 2008; RINEHART et al., 2004; YOUNG et al., 2010), embora ainda seja pouco difundida no Brasil.

As UCs marinhas do Brasil se encontram, em sua grande maioria, localizadas em áreas da plataforma continental interna, fato que se reflete no recorte espacial adotado nesta pesquisa, na qual as áreas protegidas escolhidas apresentam profundidades máximas em torno da isóbata de $50 \mathrm{~m}$ (MMA, 2007). A morfologia de fundo dessas áreas é resultado sobretudo de processos naturais, com impacto direto das diferentes posições do nível relativo do mar ao longo do tempo geológico recente, especialmente no Holoceno, e dos agentes hidrodinâmicos que atuam na esculturação do relevo de fundo e redistribuição dos sedimentos fluviais que atingem as áreas costeiras próximas (SHEPARD, 1973). Os atuais fundos marinhos aqui investigados foram, em condições estáticas pretéritas, alternadamente áreas emersas ou submersas. Isso permitiu a formação de sistemas praiais e planícies costeiras que durante o último máximo regressivo sofreram forte dissecação, com a escavação e estabelecimento de redes de drenagens, canais bem definidos, bacias hidrográficas e cabeceiras 
de drenagem, entre outras morfologias continentais. Em fases transgressivas subsequentes foram inundadas e sofreram sedimentação marinha ou lagunar, biogênica ou siliciclástica, gerando um complexo histórico de erosão e sedimentação nesses ambientes, moldado por diferentes agentes (ANGULO; LESSA; SOUZA, 2006; SUGUIO et al., 1985; SUGUIO; TESSLER, 1984).

Diferentes tipos de costa são reconhecidos no litoral brasileiro, onde o suprimento de sedimentos, a herança geológica e a energia das ondas, do vento e de marés são as principais forças de primeira ordem que acabam por diferenciar e individualizar esses setores, tendo a variação do nível do mar no período Quaternário representado uma força de segunda ordem, agindo em escala espacial e principalmente temporal distinta (DOMINGUEZ, 2004). Como característica geral, o fundo marinho da plataforma continental brasileira apresenta diversidade nos processos de sedimentação e na cobertura sedimentar ao longo da variação latitudinal da linha costa, além de baixa declividade média e largura variável de dezenas a pouco mais de cem quilômetros (BRASIL, 2006; EKAU; KNOPPERS, 1996; KNOPPERS; EKAU; FIGUEIREDO, 1999; MAHIQUES et al., 2010). Apresenta ainda paleodrenagens e paleoincisões recobertas pela atual sedimentação marinha e costeira, seja suavizando a sua presença ou pelo total preenchimento com sedimentos (CONTI; FURTADO, 2009; FAGHERAZZI et al., 2008; FURTADO; BONETTI FILHO; CONTI, 1996; WESCHENFELDER et al., 2008), sendo que em alguns casos essas paleodrenagens se conectam (ou conectavam) com a atual rede hidrográfica da planície sedimentar costeira e dos embasamentos cristalinos adjacentes (ABREU; CALLIARI, 2005; ARTUSI; FIGUEIREDO JR., 2007; CONTI; FURTADO, 2009; WESCHENFELDER et al., 2010) .

Nesse artigo será apresentada uma análise do relevo de fundo das unidades de conservação: Parque Nacional Marinho de Fernando de Noronha (PARNAMAR Noronha), Parque Nacional Marinho de Abrolhos (PARNAMAR Abrolhos) e da Reserva Biológica Marinha do Arvoredo (REBIOMAR Arvoredo), representados na figura 1 , e seus entornos, a partir da compartimentação automatizada de feições morfológicas de fundo com auxílio da rotina Benthic Terrain Modeler - BTM (NOAA, 2010; WRIGHT et al., 2005) e da determinação de padrão de paleodrenagens que possam ainda estar associados às atuais condições morfológicas.

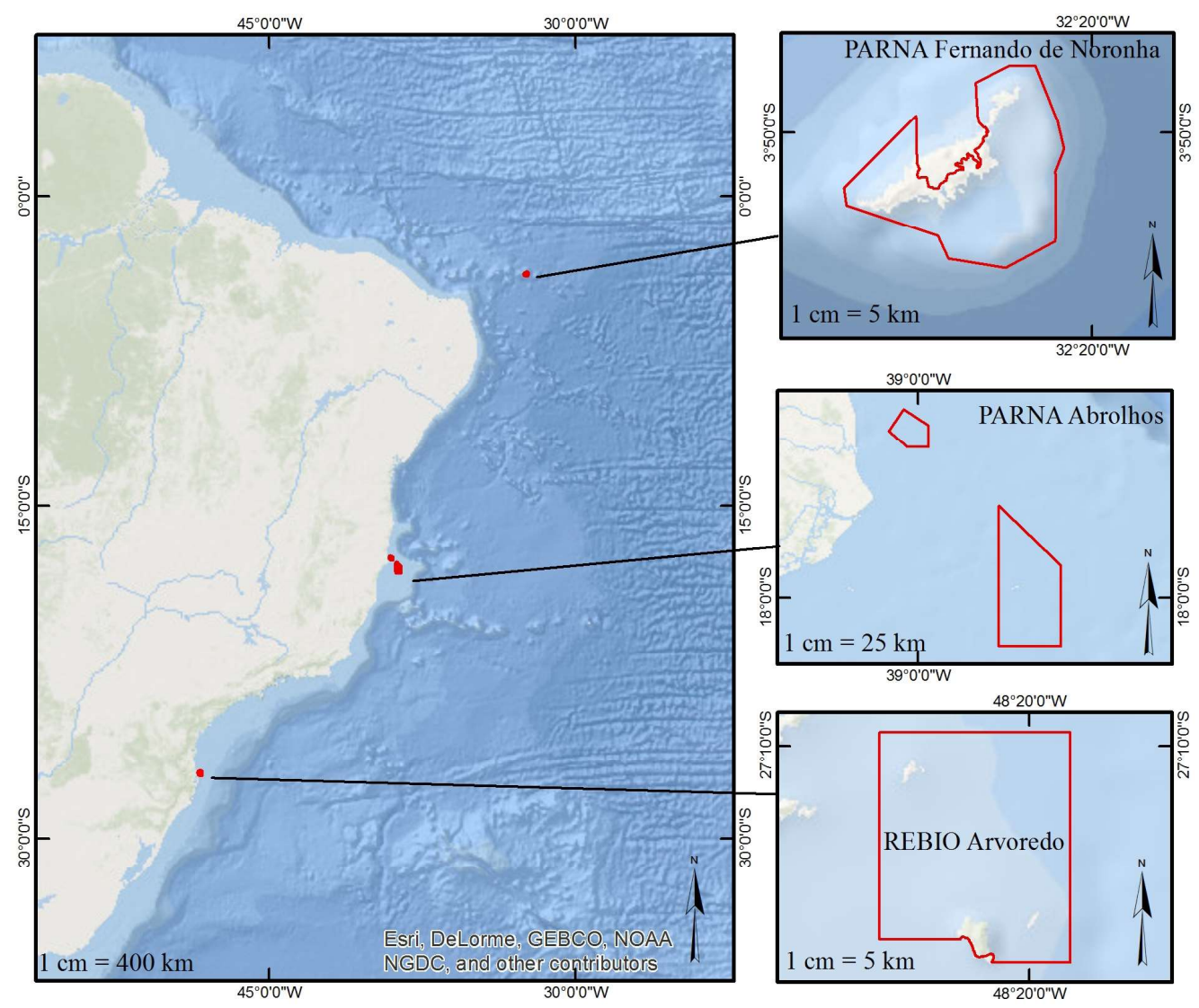

Figura 1 - Unidades de Conservação estudadas. 


\section{Caracterização das Áreas de Estudo}

\section{PARNAMAR de Fernando de Noronha}

O PARNAMAR de Fernando de Noronha possui aproximadamente 11.270 ha de área, representa 0 ambiente estudado mais afastado da costa brasileira e está localizado na Região Nordeste da Zona Econômica Exclusiva (ZEE) brasileira (IBAMA, 2005), onde predominam as águas quentes da corrente Sul Equatorial. Sua localização e características geofísicas: amplos fundos rígidos, penetração de luz abundante e baixa turbidez da água, (função da baixa disponibilidade de sedimentos terrígenos e pobre rede hidrográfica), propiciam condições especificas para a formação de recifes de corais e ecossistemas altamente diversificados, sendo o litoral dominado por dunas, falésias, e cordões litorâneos (MMA, 2007), estando sob regime de macromarés (MMA, 2008).

Sua formação está associada à cadeia vulcânica penetrante em fraturas do assoalho marinho, resultante de deslocamento de placa continental, denotando grande influência de estruturas da litosfera oceânica em sua gênese e forma. Sua localização está a leste de uma cadeia de montes submarinos, cuja orientação é leste-oeste, e que atualmente se encontram erodidos subaeriamente pela ação marinha. Com a extinção do vulcanismo local a cerca de 1,8 Ma e consequente erosão, parte desses montes podem ser caracterizados como guyots, atualmente localizados a cerca de $100 \mathrm{~m}$ de profundidade e recobertos preferencialmente por calcários biogênicos (ALMEIDA, 2006).

Esse arquipélago, constituído atualmente por 21 ilhas e área emersa de $26 \mathrm{~km} 2$, está afastado a cerca de $354,0 \mathrm{~km}$ de Natal. Seu relevo irregular está relacionado à zona de fratura transversal de montes vulcânicos submarinos, sendo que a porção insular representa um monte cônico repousante sobre o assoalho oceânico de $4000 \mathrm{~m}$ de profundidade. Situada em profundidade média de $100 \mathrm{~m}$, a plataforma marinha de Fernando de Noronha apresenta cerca de $20 \mathrm{~km}$ de diâmetro ao redor das áreas atualmente emersas. Sua atual forma é também resultado das variações do nível do mar, em especial nos últimos 15 mil anos, quando foram definidos os atuais contornos das ilhas a partir, principalmente, da ação da subida dos níveis marinhos. Antigos campos de dunas, evidenciados atualmente pelas existência do Arenito das Caracas, também estão associados a tais variações, sendo resultado do transporte, pelos ventos de ESE, de grande quantidade de areia de paleopraias que atualmente se encontram a $10 \mathrm{~m}$ ou mais abaixo da atual linha de costa. (IBAMA, 2005).

As ilhas apresentam pontões, tômbolos e praias delimitadas por pontas rochosas, onde ocorrem distintas baías e enseadas, e onde o transporte de sedimentos por ondas se encontra restrito a domínio das unidades fisiográficas separadas pelos embasamentos (ALVES; CASTRO, 2006). Oceanograficamente, a área do arquipélago apresenta duas zonas diferenciadas em função do regime de ondas e ventos: mar de dentro (face do arquipélago voltada a NW), onde se situa a maioria das praias e onde há menos ação dos ventos alísios e correntes de SE, e mar de fora (face voltada a SE), ambiente de maior energia (SERAFINI; FRANÇA; ANDRIGUETO-FILHO, 2010).

\section{PARNAMAR de Abrolhos}

O PARNAMAR de Abrolhos está geograficamente localizado na Região Central da ZEE brasileira (BRASIL, 2006) e possui cerca de 68.880 ha de área, divididos em duas glebas: ao norte, chamada de Recifes das Timbebas; e ao sul, chamada de Parcel dos Abrolhos. Atualmente essa UC passa por controversa proposta de ampliação que totalizariam em seu território cerca de 3\% da ZEE brasileira (ICMBIO, 2012). Está situado em uma zona de micromarés e dentro dos limites do Banco de Abrolhos, região anômala da plataforma continental por apresentar largura de aproximadamente $240 \mathrm{~km}$, contra média de $40 \mathrm{~km}$ (IBAMA, 1991), compreendendo o alargamento da plataforma continental entre a foz dos rios Jucuruçu e Doce e gerado pelo retrabalhamento dos sedimentos do grupo Barreiras ao longo das oscilações do nível do mar (ANDRADE et al., 2003; MARCHIORO et al., 2005). O Banco de Abrolhos representa ainda a maior seção da plataforma continental brasileira, além de abrigar o ambiente coralíneo mais setentrional do Oeste do Atlântico Sul (IBAMA, 1991; ICMBIO, 2012; LEÃO; KIKUCHI, 2005).

A Formação Abrolhos, onde se encontra o PARNAMAR Abrolhos, representa uma "associação litológica complexa, englobando rochas básicas de composição toleítica a alcalina com intercalações de rochas vulcanoclásticas e rochas sedimentares" (FERREIRA, 2010). Sua origem e estrutura estão associadas a um alto batimétrico chamado de Alto de 
Santa Bárbara e a diques de diabásio oriundos de intrusão vulcânica que, por sua vez, representaram uma acresção à plataforma continental (LEÃO, 2002). Tais intrusões não representariam fenômenos de plumas ascendentes, mas seriam caracterizadas como hotspots intraplacas e relacionados a reativação de zonas de fraturas na crosta oceânica. Rochas vulcânicas, intrusivas e vulcanoclásticas representam os tipos litológicos predominantes, sendo as atividades vulcânicas submarinas mais representativas (FERREIRA, 2010).

A depressão de Abrolhos é conhecida como uma paleolaguna, exposta subaeriamente, e profundamente escavada pelo sistema de drenagem fluvial em período pretérito, e onde a partir dos últimos 8000 anos teve cessada a sedimentação continental, dando lugar a deposição marinha de carbonatos biogênicos. As feições batimétricas bem evidentes sugerem a confluência de algumas drenagens contemporâneas sobre a planície então exposta, dividindo-a em duas zonas, e evidenciando dois canais distintos (ANDRADE et al., 2003; SERAFINI; FRANÇA; ANDRIGUETO-FILHO, 2010). Morfologicamente, esses dois canais separam estruturas coralinas em diferentes profundidades e formas: Arco Costeiro, com chapeirões fundidos em bancos recifais, e o Arco Externo, com os chapeirões isolados e não foram unidos por coalescimento lateral (ICMBIO, 2012; RUDORFF; KAMPEL; SUMIDA, 2009). Sua morfologia, paralela a costa e formada por dois arcos consecutivos largamente expostos nas marés mais baixas, juntamente com características hidrodinâmicas de correntes de ondas de mares, servem de barreira topográfica e hidrodinâmica para as águas da Corrente do Brasil, dominantes no arquipélago (PIRES; CASTRO; RATTO, 1999).

No território do Parque se situam três ilhas maiores e uma ilhota menor, com extensão entre 100 e $300 \mathrm{~m}$ aproximadamente, e altitude média que varia entre 13 e 36 metros, onde se desenvolvem feições de cuestas e onde as escarpas mais elevadas se encontram orientadas para o quadrante sul. Praias arenosas circundam parte das ilhas, onde rochas sedimentares afloram e surgem feições como praias de matacões e paredões abruptos (IBAMA, 1991; IBGE et al., 1995). A turbidez das suas águas tem relação direta com a ressuspensão de sedimentos das bordas dos arcos, e não com a descarga fluvial, onde predominam partículas carbonáticas de origem coralínea ou areia lamosa das camadas de fundo marinho. Nas calmarias de verão, entre os meses de dezembro e fevereiro, predominam águas com menor concentração de sólidos em suspensão, enquanto que durante as mudanças de vento e nas marés de sizígia ocorrem os aumentos de turbidez (IBAMA, 1991; LEIPE et al., 1999).

\section{REBIOMAR do Arvoredo}

Localizada ao sul do Trópico de Capricórnio, a REBIOMAR Arvoredo está geograficamente localizada na Região Sul da ZEE brasileira (BRASIL, 2006), sendo a mais próxima do continente dentre as áreas estudadas. Nesse setor, a presença sazonal da Água Central do Atlântico Sul (ACAS) sobre a plataforma continental, associada a frequentes ressurgências ao longo da costa, contribuem para o aumento de produtividade, assim como o encontro das correntes do Brasil e Malvinas (atualmente reinterpretada como sendo uma água de mistura formada pela contribuição do Rio da Prata), que influenciam diretamente na composição da fauna local (MMA, 2007). Situa-se em área sob regime de micromarés da Bacia Sedimentar de Santos, onde predominam ambientes costeiros tais como costões rochosos, praias, lagunas e manguezais (MMA, 2008). A Unidade de Conservação (UC) possui área de aproximadamente 17.600 ha, que engloba três ilhas principais e alguns calhaus (CHLUDINSKI, 2002), basicamente formados por rochas graníticas cortadas por diques básicos-intermediários de variadas espessuras (TOMAZZOLI; LIMA, 2004).

A geologia local é caracterizada por duas grandes unidades: embasamento cristalino pré-cambriano e bacia sedimentar do Paraná, sendo que as ilhas e parcéis atualmente existentes, como a própria Ilha do Arvoredo, se correlacionam com o soerguimento do segmento sul da Serra do Mar. As estruturas das rochas, ilha e calhaus parece ser fortemente condicionadas pelos dois principais falhamentos e suas respectivas direções, como no caso do Saco da Bala e da Ilha Deserta, sendo que tais rochas são cortadas por diques de diabásio de granulação fina e coloração escura (CHLUDINSKI, 2002). COOPER et al., (2016), por sua vez, afirmam que a Baia de Tijucas passou por diferentes processos sedimentares evolutivos durante o Holoceno, até atingir sua configuração geomorfológica atual, fato evidenciado pela diversidade de ecofácies identificadas em recente mapeamento sísmico ali conduzido. 
Toda a área da REBIOMAR Arvoredo se encontra na plataforma continental do sul do Brasil, onde são encontradas, de modo geral, areias recobrindo o fundo (BRASIL, 2006). A topografia local apresenta baixa declividade, com isóbatas alinhadas aproximadamente de forma paralela com a atual linha de costa (ABREU, 2010; ZEMBRUSKI, 1979). No entorno da Unidade de Conservação (incluindo a Baía de Tijucas) as profundidades atingem 44,0 $\mathrm{m}$ (média de $16,3 \mathrm{~m}$ ), com as isóbatas se apresentando distribuídas uniformemente, sendo que na porção Oeste da Reserva várias elevações se fazem presentes.

Destacam-se na morfologia da área um alto batimétrico ao norte da Ilha das Galés, além de um pequeno vale sentido NW entre as ilhas do Arvoredo e Deserta, que pode ter implicações importantes na mistura de massas d'água que ocorre no interior da UC e suas consequências na biodiversidade da Reserva (CHLUDINSKI, 2002). Na área de estudo são encontrados sedimentos arenosos e lamosos, além de suas combinações, à vezes com concentrações de biodetritos (ABREU, 1998), contando ainda com a presença de parcéis e substratos rochosos consolidados (SANTOS et al., 1996). Concentrações de carbonato atingiram cerca de $37 \%$ na porção central da UC, e concentração de matéria orgânica que variaram entre valores inferiores a $1 \%$ e pouco acima de $14 \%$, com destaque à grande concentração do material na Baía de Tijucas (PAQUETTE et al., 2016).

\section{Materiais e Métodos}

Os dados de batimetria utilizados nesse trabalho foram compilados de cartas náuticas disponibilizadas pela Marinha do Brasil (cartas 1902, 1903, 52 e 1310) complementados por dados cedidos pelo projeto Sistema de Modelagem Costeira (SMC), do Laboratório de Oceanografia Costeira da Universidade Federal de Santa Catarina (UFSC). A partir dos arquivos vetoriais na forma de pontos foi realizada uma interpolação dos dados batimétricos, com resolução espacial final de $200 \mathrm{~m}$, utilizando a técnica Vizinho Natural (Natural Neighbor), para cada um dos recortes espaciais definidos. Este interpolador apresenta bom desempenho na geração de Modelos Digitais de Terreno (MDT), sobretudo quando a base possui alguns setores com alta e outros com baixa concentração de pontos, como no caso de sondagens batimétricas obtidas a partir de cartas geradas em escalas distintas (SIBSON, 1981). As isóbatas presentes nas Cartas Náuticas não foram digitalizadas por considerar-se que essas já representam resultados da interpolação dos dados pontuais originais. Em Fernando de Noronha e Abrolhos aplicou-se o recorte espacial a partir da cota de $120 \mathrm{~m}$ de profundidade $(-120 \mathrm{~m})$, face às grandes profundidades que circundam essas UCs e que iriam influenciar nos resultados da análise morfológica proposta.

As grades de batimetria obtidas a partir das interpolações (formato matricial) sofreram posterior supressão das áreas emersas (figuras 2, 3 e 4) e posteriormente alimentaram a extensão Benthic Terrain Modeler (BTM), desenvolvida pela Oregon State University em parceria com a National Oceanic and Atmospheric Administration (NOAA), que opera integrada ao sistema ArcGIS. Nela, foram geradas grades de Índices de Posicionamento Batimétricoo (Bathymetricc Position Indexes - BPIs) local (fine) e ampla (broad) (FBPI e BBPI, nas siglas originais) que realizam a análise da vizinhança próxima e distante, respectivamente, a partir do emprego de dois raios de análise (interno e externo) diferenciados.

O BPI foi adaptado do Topographic Position Index (JENNESS, 2006) e representa um índice de localização relativa determinado por um algoritmo matemático que analisa a posição de um ponto (pixel) em relação à média dos seus vizinhos, classificando-o como neutro, positivo, moderadamente positivo, muito positivo ou negativo, moderadamente negativo e muito negativo (CAMPOS, 2011; LUNDBLAD et al., 2006; NOAA, 2010). Posterior padronização foi realizada em procedimento próprio, resultando em mapas de Índice de Posicionamento Batimétrico Padronizados, que serviram de base para o próximo procedimento. A esses últimos resultados foram posteriormente aplicadas as bibliotecas de classificação de feições, que determinam a classe morfológica em função dos dados de posicionamento padronizados nas duas escalas de análise, associados à profundidade e declividade. Para esse trabalho utilizou-se os valores para a definição dos raios de vizinhança conforme a tabela 1 (a unidade dos raios é o número de células): 


\section{BATIMETRIA}

\section{Parque Nacional Marinho de Fernando de Noronha e entorno}
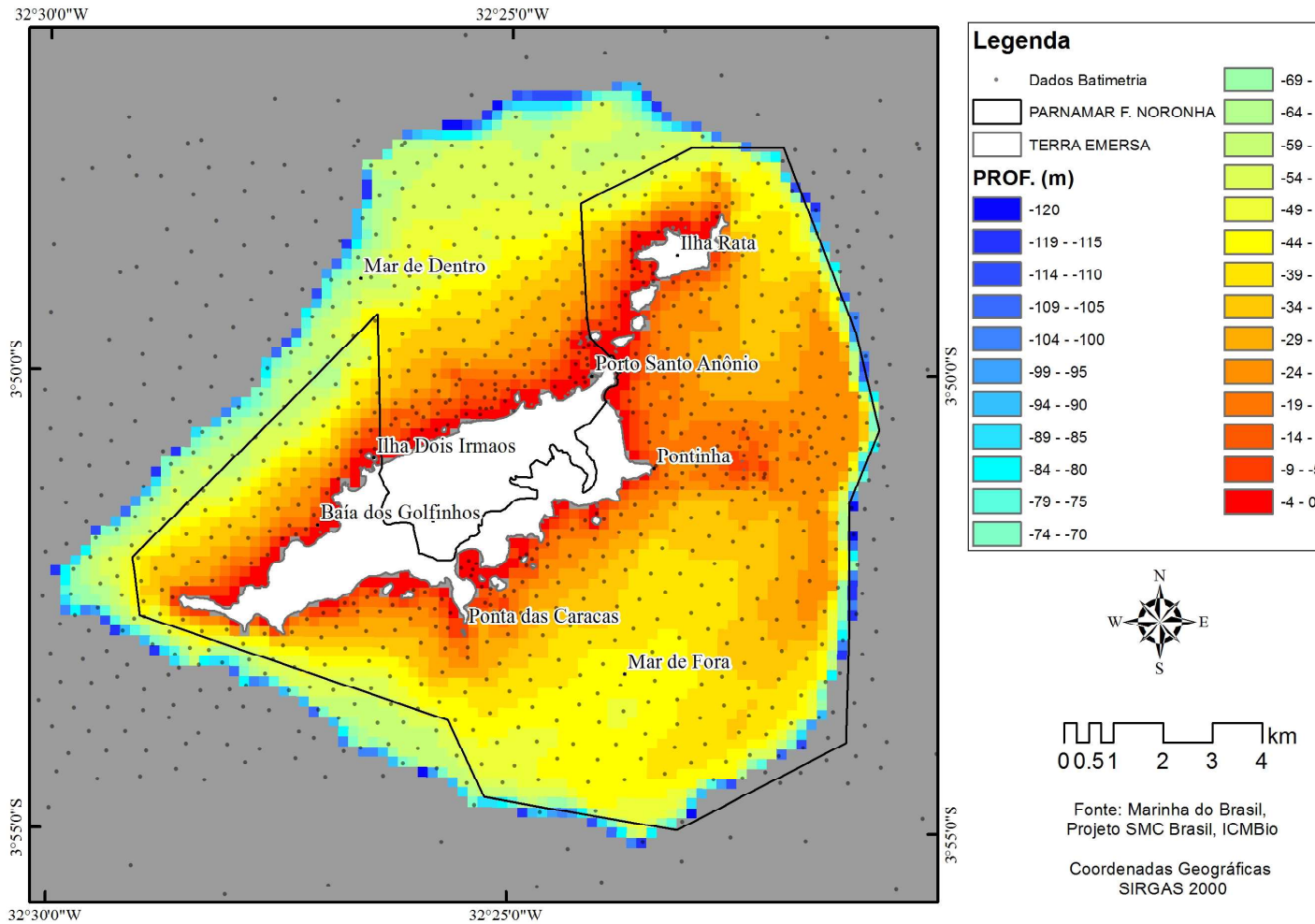

Fonte: Marinha do Brasil, Fonte: Marinha do Brasil,
Projeto SMC Brasil, ICMBio Coordenadas Geográficas

Figura 2 - Batimetria do PARNAMAR Fernando de Noronha e entorno. A porção cinza corresponde à área submersa não estudada.

BATIMETRIA

Parque Nacional Marinho de Abrolhos e entorno
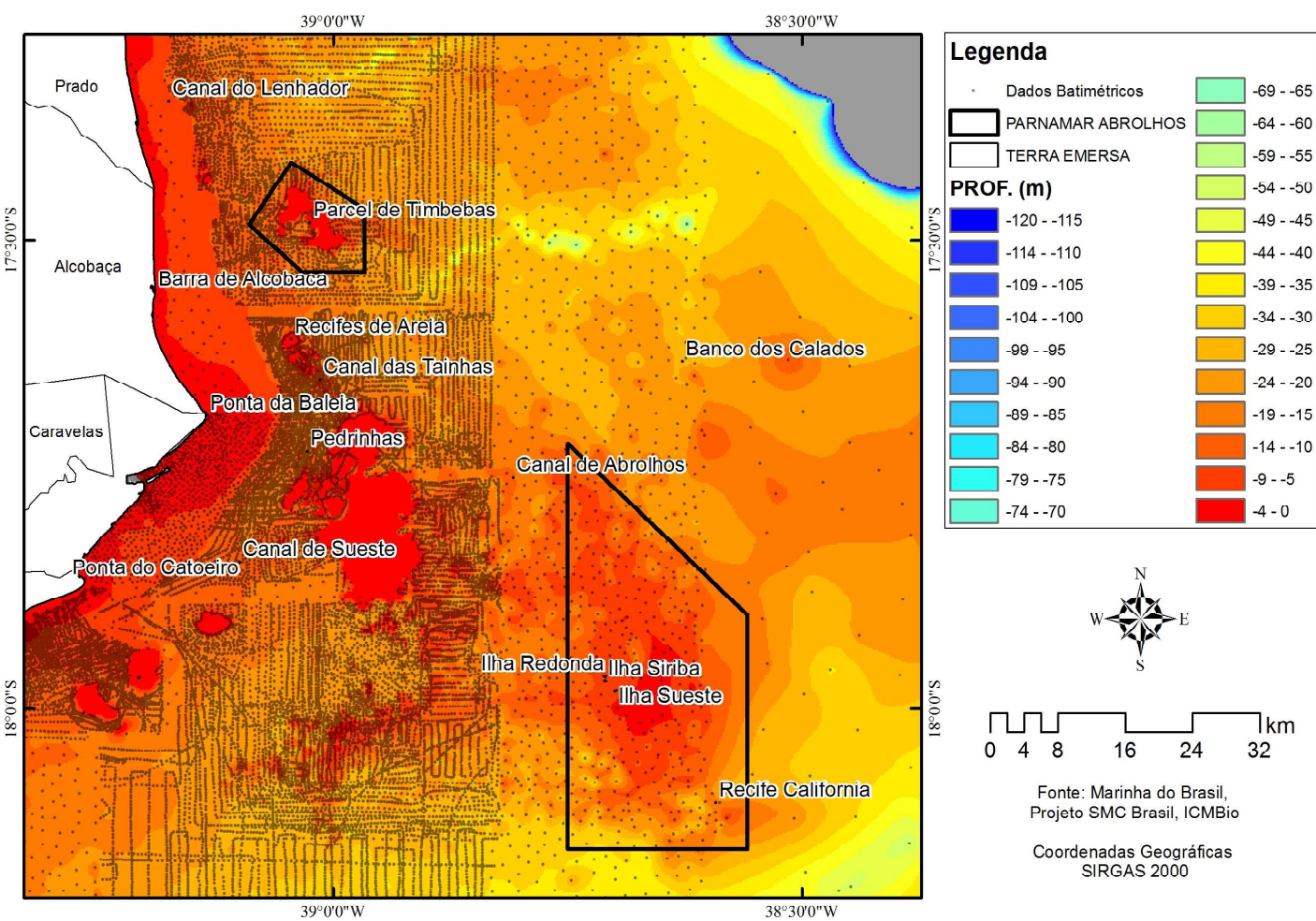

Figura 3 - Batimetria do PARNA Abrolhos e entorno. A porção cinza corresponde a área submersa não estudada. 
BATIMETRIA

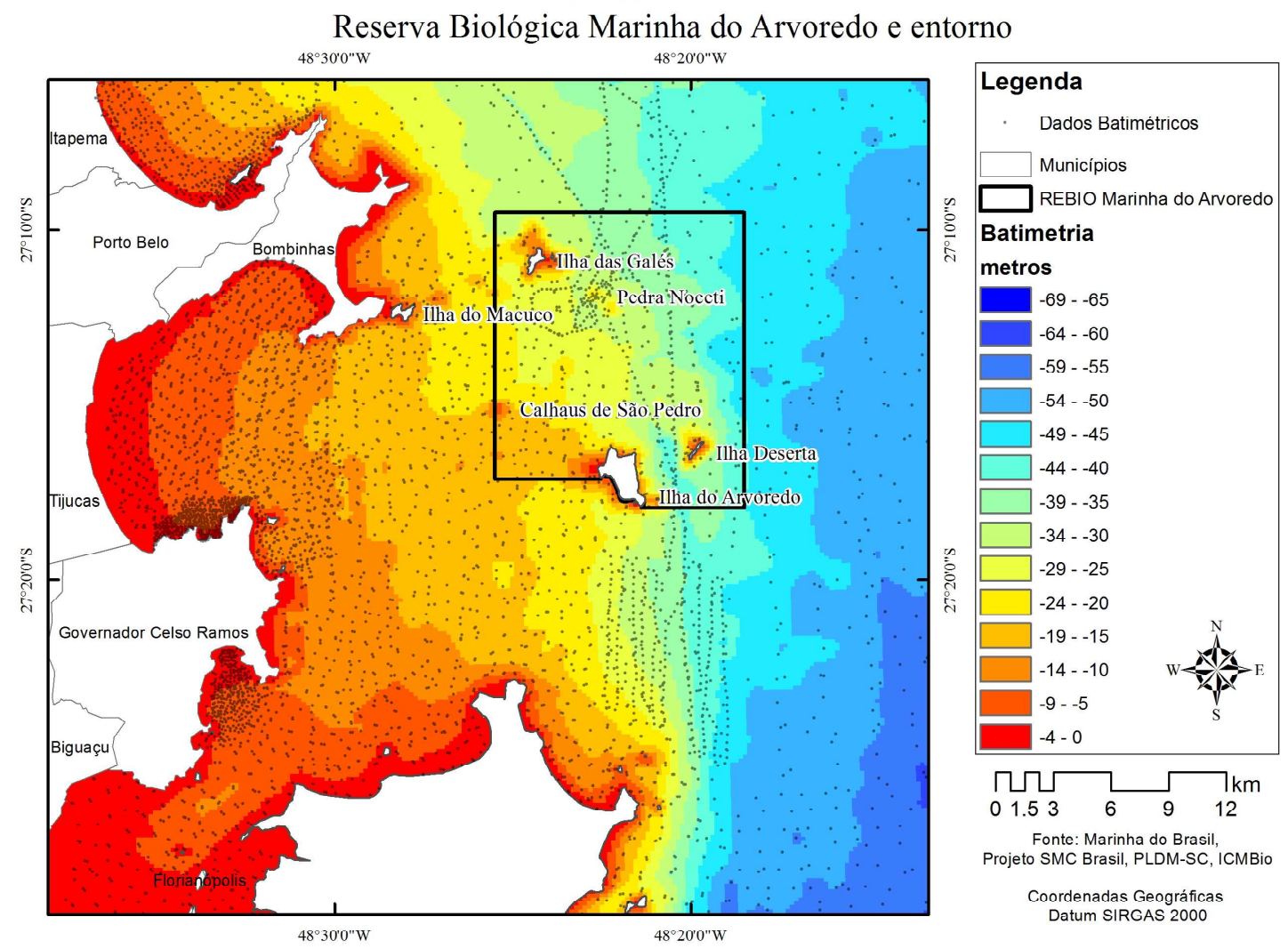

Figura 4 - Batimetria da REBIOMAR Arvoredo e entorno, com as principais toponímias.

Tabela 1: Número de células utilizado nos raios de análise do BTM para as escalas ampla e local.

\begin{tabular}{l|c|c|c}
\hline & RAIO INTERNO & RAIO EXTERNO & FATOR DE ESCALA \\
\hline BPI AMPLO (BBPI) & 1 & 32 & $6400 \mathrm{~m}$ \\
\hline BPI LOCAL (FBPI) & 1 & 8 & $1600 \mathrm{~m}$ \\
\hline
\end{tabular}

A biblioteca de classificação (tabela 2 e figura 5), que interpreta os valores de BPI, profundidade e declividade e os transforma em classes de relevo em duas escalas (zonas e estruturas), foi adaptada de LUNDBLAD, (2004) que realizou estudos em águas mais profundas e além da plataforma continental. $\mathrm{Na}$ adaptação aqui realizada, o limite entre as feições Planície Rasa e Planície foi alterado de -22 m, para - 10 $\mathrm{m}$, por melhor representar uma transição dos ambientes locais influenciados diretamente pela energia de ondas
(MMA, 2002). Os limites de classificação entre as feições estruturais de maior e menor escala também foram alterados, de 100 para 35 (escala BPI), inferindo por sua vez maior sensibilidade à interpretação da variação de feições.

Para a determinação das paleodrenagens das áreas de entorno foram realizadas análises a partir das mesmas batimetrias interpoladas descritas anteriormente (figuras 2, 3 e 4). Utilizando as grades de dados em formato raster, realizou-se um procedimento de preenchimento ( fill) dessas grades que representam os Modelos Digitais de Terreno e aplicou-se o procedimento analítico proposto por CONTI; FURTADO (2009) . De posse das novas grades batimétricas, já após o processamento citado acima, foram realizadas no ArcGIS consecutivamente as análises espaciais: Flow Direction, Flow Accumulation, Con (com limites de "value" > 1000 para Arvoredo, 100 para Noronha e 500 para Abrolhos ${ }^{1}$; sempre utilizando a simplificação, ou suavização, das linhas resultantes, e constant value

${ }^{1}$ Esses valores representam o número de células que contribuem com fluxo para a célula em análise. Por isso, a partir de uma mesma resolução espacial ( $200 \mathrm{~m}$ nesse caso) e com escalas espaciais diferentes no mapeamento base, é que valores diferentes puderam ser usados para a definição das redes de drenagem. 
=1) e finalmente Stream to Feature, onde definiu-se uma proposta de rede vetorial de paleodrenagem. A ferramenta Basin foi, então, empregada para delinear uma proposta de delimitação das paleobacias submersas.

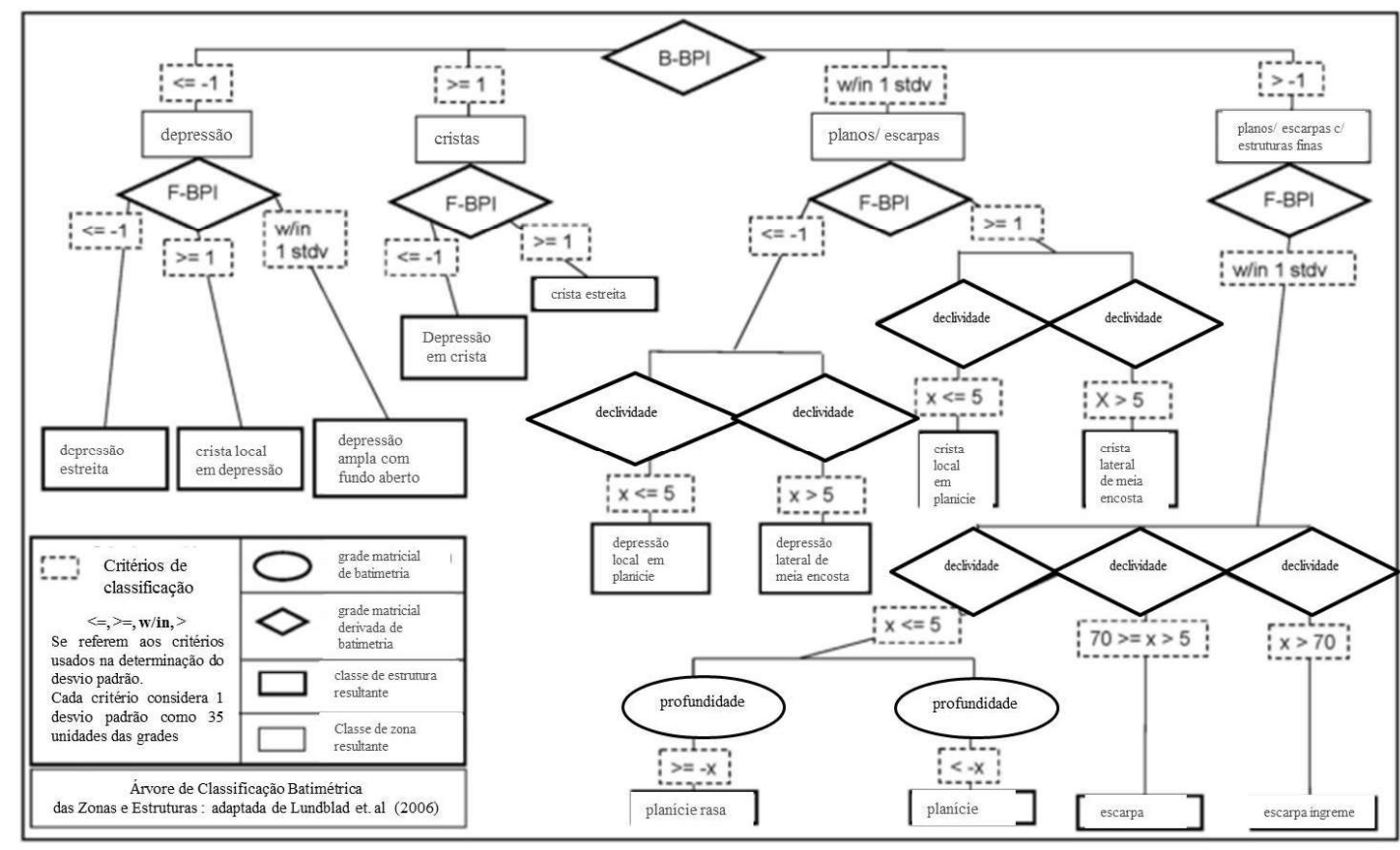

Figura 5 - Fluxograma da biblioteca de classificação utilizada e referente à tabela 2.

Tabela 2: Biblioteca de classificação utilizada nesse trabalho. Os valores 100 e -100 foram alterados para 35 e -35 , e $-22 \mathrm{~m}$ para $10 \mathrm{~m}$, respectivamente. $\mathrm{LI}=$ Limite Inferior; LS=Limite Superior; BBPI=Índice Amplo; FBPI: Índice Local.

\begin{tabular}{c|c|c|c|c|c|c|c|c}
\hline & LI_BBPI & LS_BBPI & LI_FBPI & LS_FBPI & LI_DECL & LS_DECL & LI_PROF & LS_PROF \\
\hline Depressão Es treita & - & -35 & - & -35 & - & - & - & - \\
\hline Depressão Local em Planicie & -35 & 35 & - & -35 & - & $5^{\circ}$ & - & - \\
\hline Depressão em Encosta & -35 & 35 & - & -35 & $5^{\circ}$ & - & - & - \\
\hline Depressão em Crista & 35 & - & -35 & - & - & - & - & - \\
\hline Depr. Ampla com Fundo Aberto & - & -35 & -35 & 35 & - & - & - & - \\
\hline Planicie Ampla & -35 & - & -35 & 35 & - & $5^{\circ}$ & - & $-10 \mathrm{~m}$ \\
\hline Planicie Rasa & 35 & - & -35 & 35 & - & $5^{\circ}$ & $-10 \mathrm{~m}$ & - \\
\hline Encosta & -35 & - & -35 & 35 & $5^{\circ}$ & $70^{\circ}$ & - & - \\
\hline Crista Local em Depressão & - & -35 & 35 & - & - & - & - & - \\
\hline Crista Local em Planicie & -35 & 35 & 35 & - & - & $5^{\circ}$ & - & - \\
\hline Quebra Lateral de Encosta & -35 & 35 & 35 & - & $5^{\circ}$ & - & - & - \\
\hline Crista Estreita & 35 & - & 35 & - & - & - & - & - \\
\hline Encosta Íngrime & -35 & - & -35 & 35 & $70^{\circ}$ & - & - & - \\
\hline
\end{tabular}

\section{Resultados e Discussão}

\section{PARNAMAR de Fernando de Noronha}

Da mesma forma que nos outros ambientes aqui estudados, embora esteja em condição ímpar aos demais com relação a sua distância da costa e profundidade circundante, as isóbatas mais rasas do entorno do Arquipélago de Fernando de Noronha apresentaram alinhamento aparente com a atual linha de costa das ilhas locais (figura 2). No que diz respeito à morfologia de fundo, observou-se a predominância, para esse local, da feição planície, sendo a planície do Mar de Fora mais extensa e representativa (figuras 6 e 7) que as demais. Essa planície se estende por todo entorno do arquipélago, entre as isóbatas de $20 \mathrm{~m}$ e $50 \mathrm{~m}$ de profundidade, sugerindo uma possível estabilização do 
nível marinho em uma posição mais profunda, o que teria permitido o desenvolvimento dessas áreas planas atualmente submersas.

Embora a partir da isóbata de $50 \mathrm{~m}$ tenha sido observado o final dessas planícies, e considerando também que o limite legal do PARNAMAR Fernando de Noronha é a isóbata de 50m (IBAMA, 2005), as grandes variações de profundidade foram observadas somente nas proximidades da isóbata de $100 \mathrm{~m}$, juntamente com algumas vertentes, e somente no mar de fora, a leste da UC e fora dessa área legalmente protegida. Estrutura mais homogênea que as demais ocorre nessa área de estudo, com transição das praias e costões para cristas estreitas, cristas locais, planícies e consequentes canais e depressões. Esse local ainda apresenta uma maior complexidade de formas na porção NE, associada a uma extensão submersa de cristas a partir do promontório da Pontinha e em direção à quebra da sua estreita plataforma continental, com provável importância biogeográfica.

Paleodrenagens foram identificadas juntamente com três principais paleomicrobacias, localizadas a NE, $\mathrm{SE}$ e $\mathrm{N}$ do arquipélago (figuras 8 e 9), com destaque novamente para a grande planície do Mar de Fora. Durante máximo regressivo de 18.000 anos AP, a cadeia de ilhas entre a principal e a Ilha Rata representaria um divisor de águas, assim como a crista que segue a partir da Pontinha em direção a leste e da crista que parte da Ponta das Caracas. A extensão da planície do Mar de Dentro parece ser fortemente influenciada pelas cristas identificadas a sul e pela grande crista em arco localizada a leste do arquipélago, contrastando com a presença de feições côncavas do Mar de Dentro. O baixo adensamento dos pontos disponíveis e extraídos da Carta Náutica, porém, pode igualmente ter influenciado na baixa variabilidade (homogeneidade) das feições encontradas nesse local.

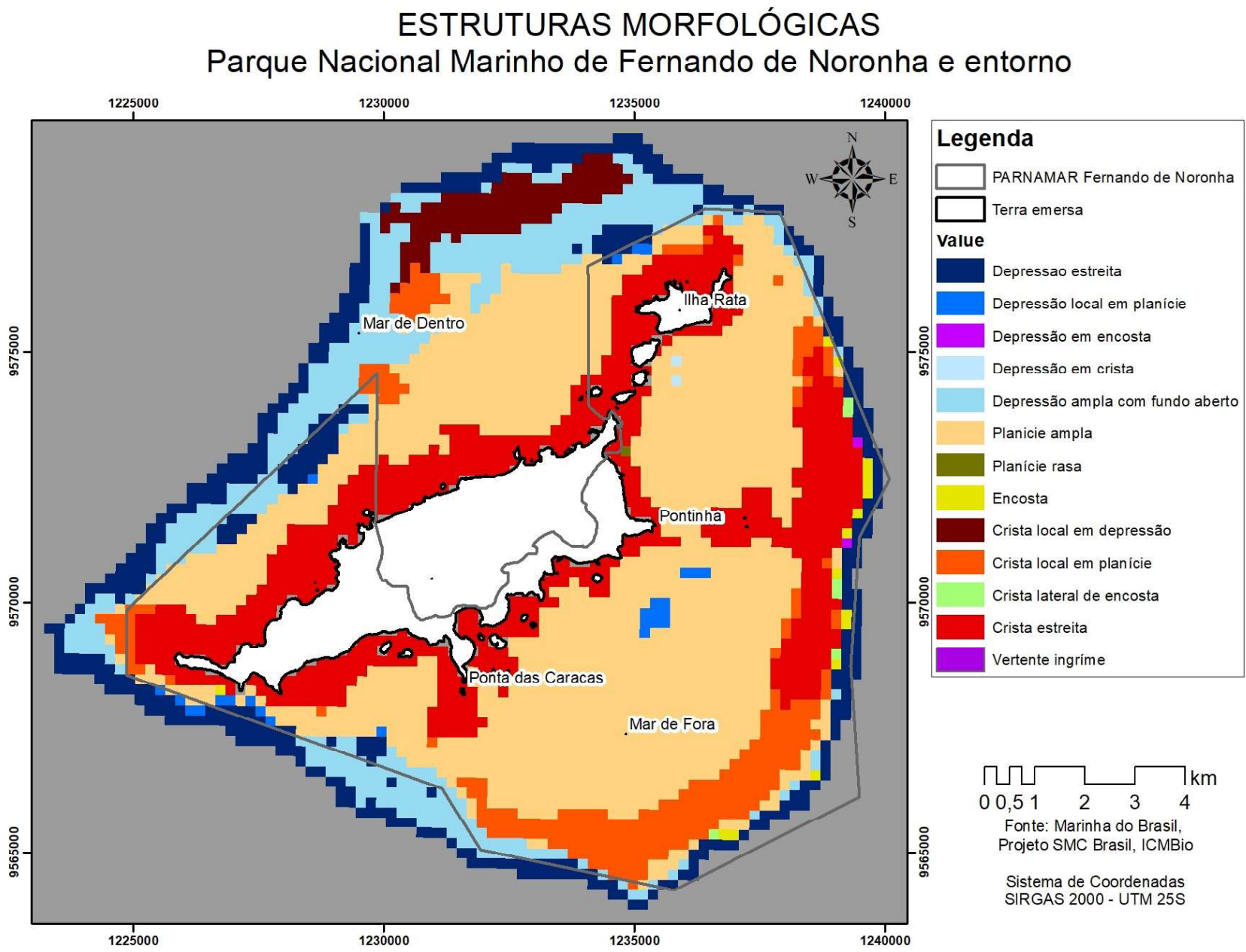

Figura 6 - Estruturas morfológicas de fundo para o PARNAMAR Fernando de Noronha e entorno. A porção cinza corresponde à área imersa não estudada. 


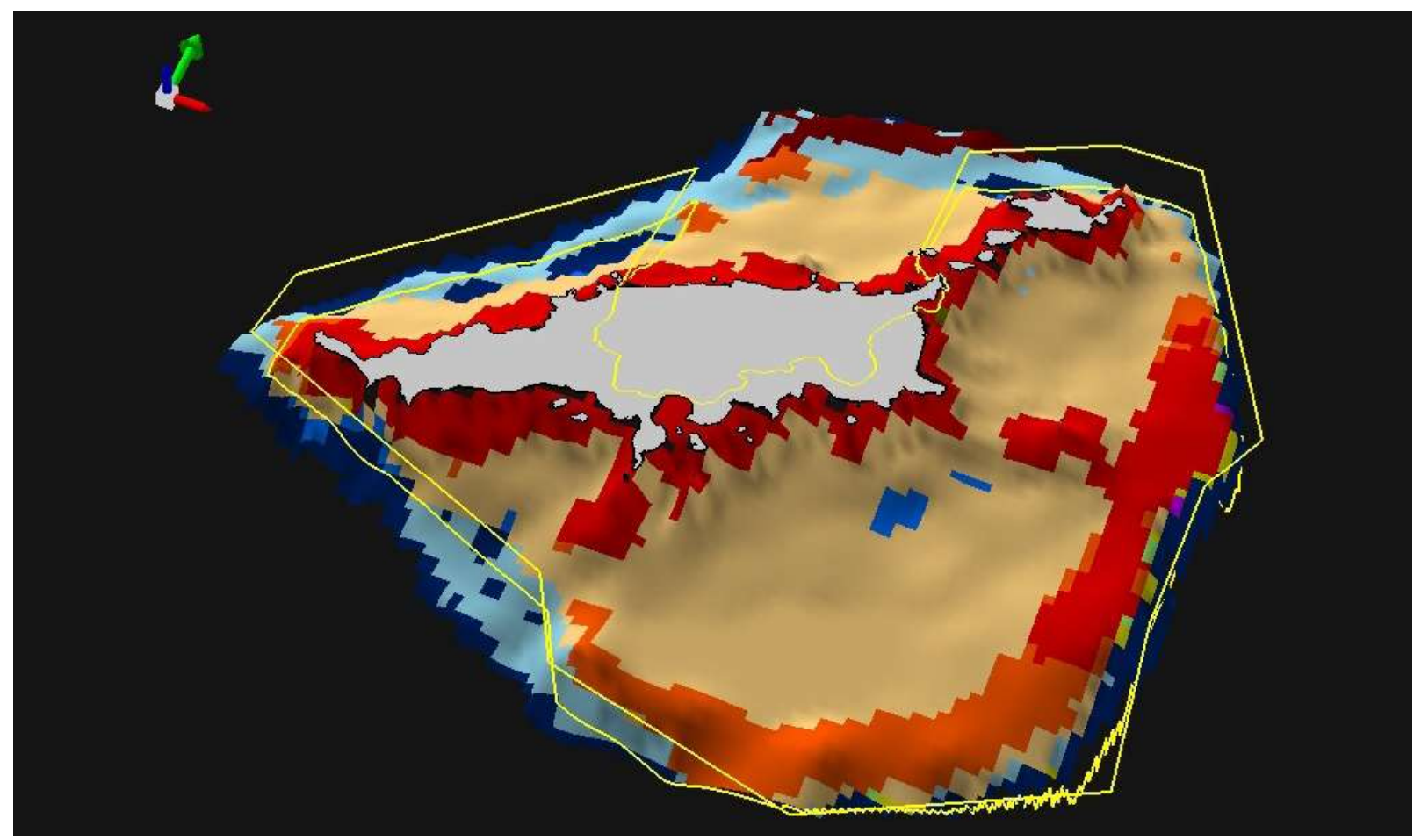

Figura 7 - Estruturas morfológicas de fundo para o PARNAMAR Fernando de Noronha e entorno, em perspectiva tridimensional. A porção negra corresponde à área imersa não estudada. Exagero vertical de 20 vezes para efeito de visualização. Vetor verde indica o norte.

\section{ZONAS MORFOLÓGICAS E PALEODRENAGENS}

Parque Nacional Marinho de Fernando de Noronha e entorno

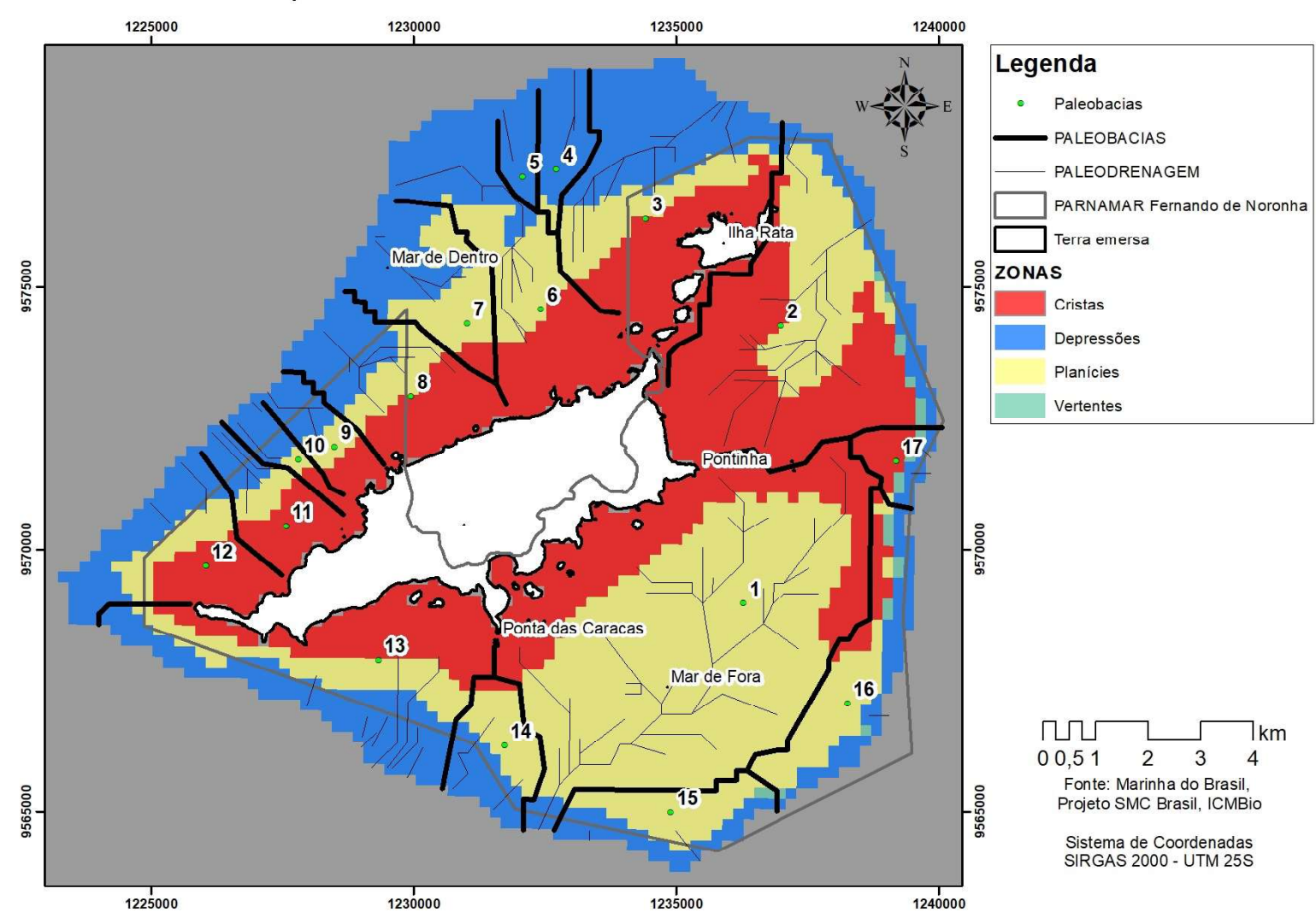

Figura 8 - Paleodrenagem e limites de paleobacias hidrográficas sobre zonas morfológicas de fundo para o PARNAMAR Fernando de Noronha e entorno. A porção cinza corresponde à área submersa não estudada. 


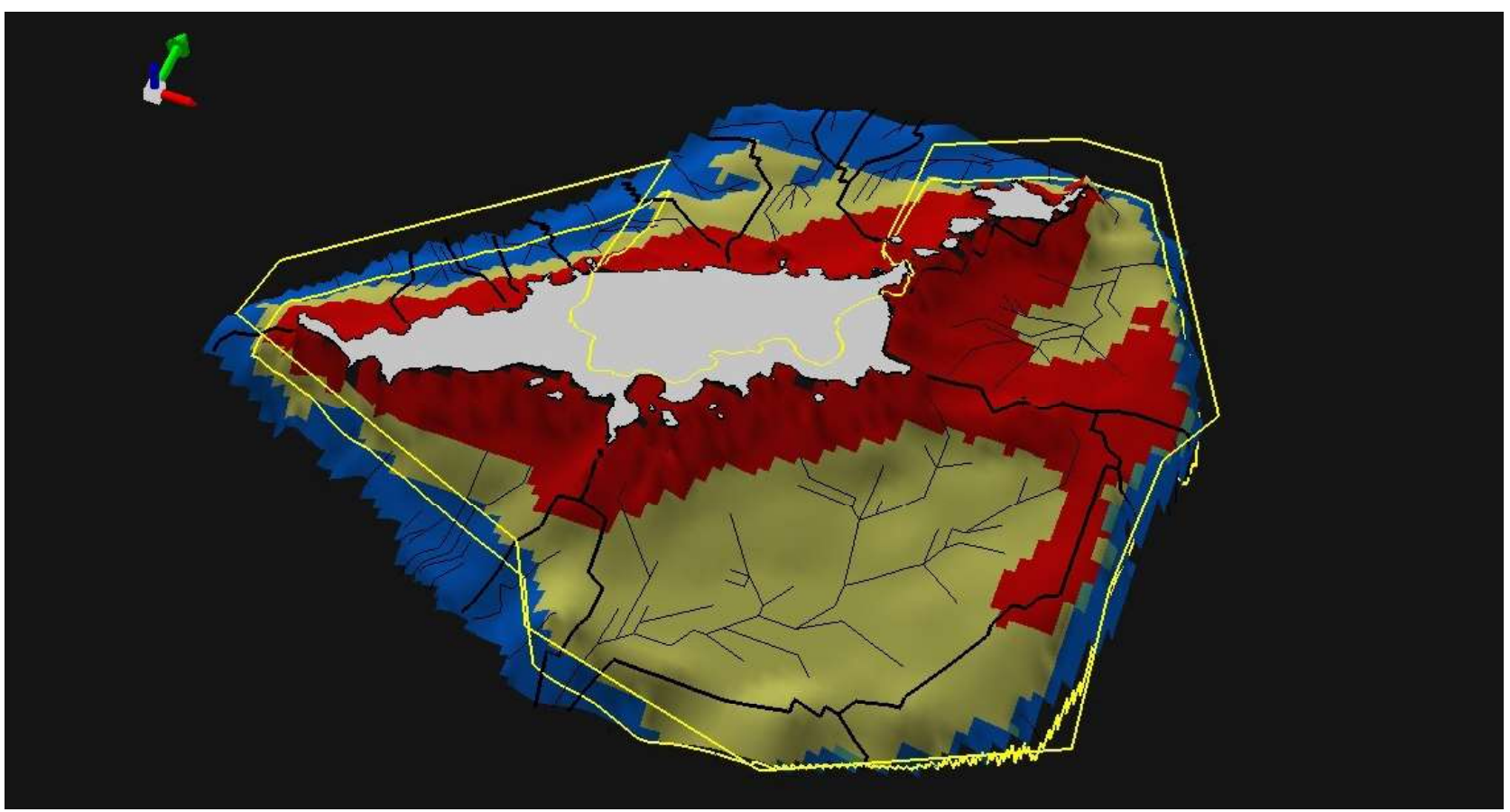

Figura 9 - Paleodrenagem e limites de paleobacias hidrográficas sobre zonas morfológicas de fundo para o PARNAMAR Fernando de Noronha e entorno, em perspectiva tridimensional. A porção negra corresponde à área submersa não estudada. Exagero vertical de 20 vezes para efeito de visualização. Vetor verde indica o norte.

\section{PARNAMAR de Abrolhos}

Na área do PARNAMAR de Abrolhos observa-se o grande prolongamento da planície costeira (figura 3), com os limites da área protegida associados a dois altos batimétricos individualizados. Chamam a atenção a batimetria acentuada a leste da parcela norte do Parque, assim como o alinhamento das isóbatas acompanhando a atual linha de costa. Uma grande complexidade de feições morfológicas também é observada nesta UC e seu entorno (figuras 10 e 11), com cristas, planícies, depressões e canais bem evidentes. Destaque específico é dado aos canais ao sul do Parcel de Timbebas, atualmente chamado de Canal de Itanhaém, e as planícies rasas da gleba do Parcel de Abrolhos, afastadas a mais de $60 \mathrm{~km}$ da costa.

Embora o crescimento das estruturas coralinas condicionado em parte pela variação do nível do mar (LEÃO, 1982), juntamente com a tendência destrutiva da última transgressão marinha, possam ter interferido na descaracterização da morfologia submersa local (VILLWOCK, 1994), pôde-se determinar possíveis paleodrenagens ao norte e ao sul da linha imaginaria que segue da Ponta da Baleia pelo Parcel das Paredes (SE) em direção a leste do Parcel de Abrolhos (figuras 12 e 13). Parte das feições morfológicas, quando comparadas com a rede hidrográfica continental atual, permite sugerir que alguns dos canais e depressões estejam associados a paleoredes de drenagem local, em função da orientação de seu eixo principal com a rede de drenagem atualmente ativa.

Todavia, deve-se ressaltar que a paelodrenagem reconstruída para a PARNAMAR de Abrolhos aparenta ser menos realista do que as obtidas para as outras duas UCs, apresentando trechos nos quais os paleocursos fluem de depressões para planícies. Tais inconsistências sugerem a menor efetividade dessa estratégia de análise espacial em plataformas carbonáticas, onde os organismos marinhos que se estabelecem após a fase transgressiva podem remodelar de forma efetiva o fundo submarino.

\section{REBIOMAR Arvoredo}

A batimetria da área da REBIOMAR Arvoredo apresentou em aguas mais rasas, em especial na Baía de Tijucas, isóbatas paralelas às linhas de costa, onde os pontões e promontórios do entorno parecem exercer influencia estrutural. Em direção a águas mais profundas tal padrão parece ser condicionado pelas Ilhas do Arvoredo, Deserta e Galés, além do Calhau de São 


\section{Caracterização Geomorfológica do Relevo Submarino de Areas Marinhas Protegidas Brasileiras}

Pedro, onde maior complexidade na distribuição das isóbatas é observada. Seguindo mais a jusante, observase a existência de um canal, já destacado por outros autores (CHLUDINSKI; BONETTI, 2002), situado entre as Ilhas do Arvoredo e Deserta, e que representa o setor de águas mais profundas nessa UC.

\section{ESTRUTURAS MORFOLÓGICAS \\ Parque Nacional Marinho de Abrolhos e entorno}

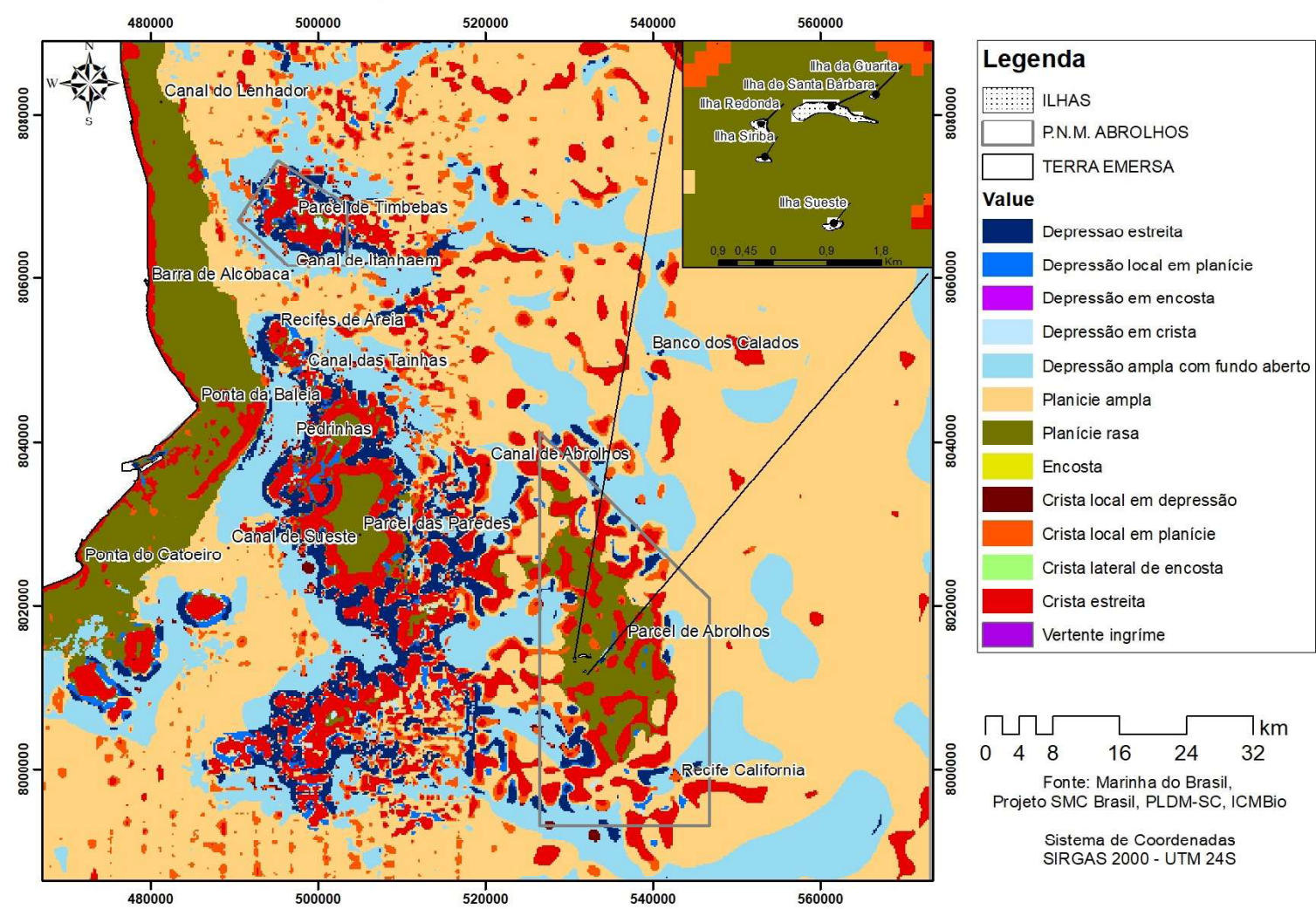

Figura 10 - Estruturas morfológicas de fundo do PARNA Abrolhos e entorno.

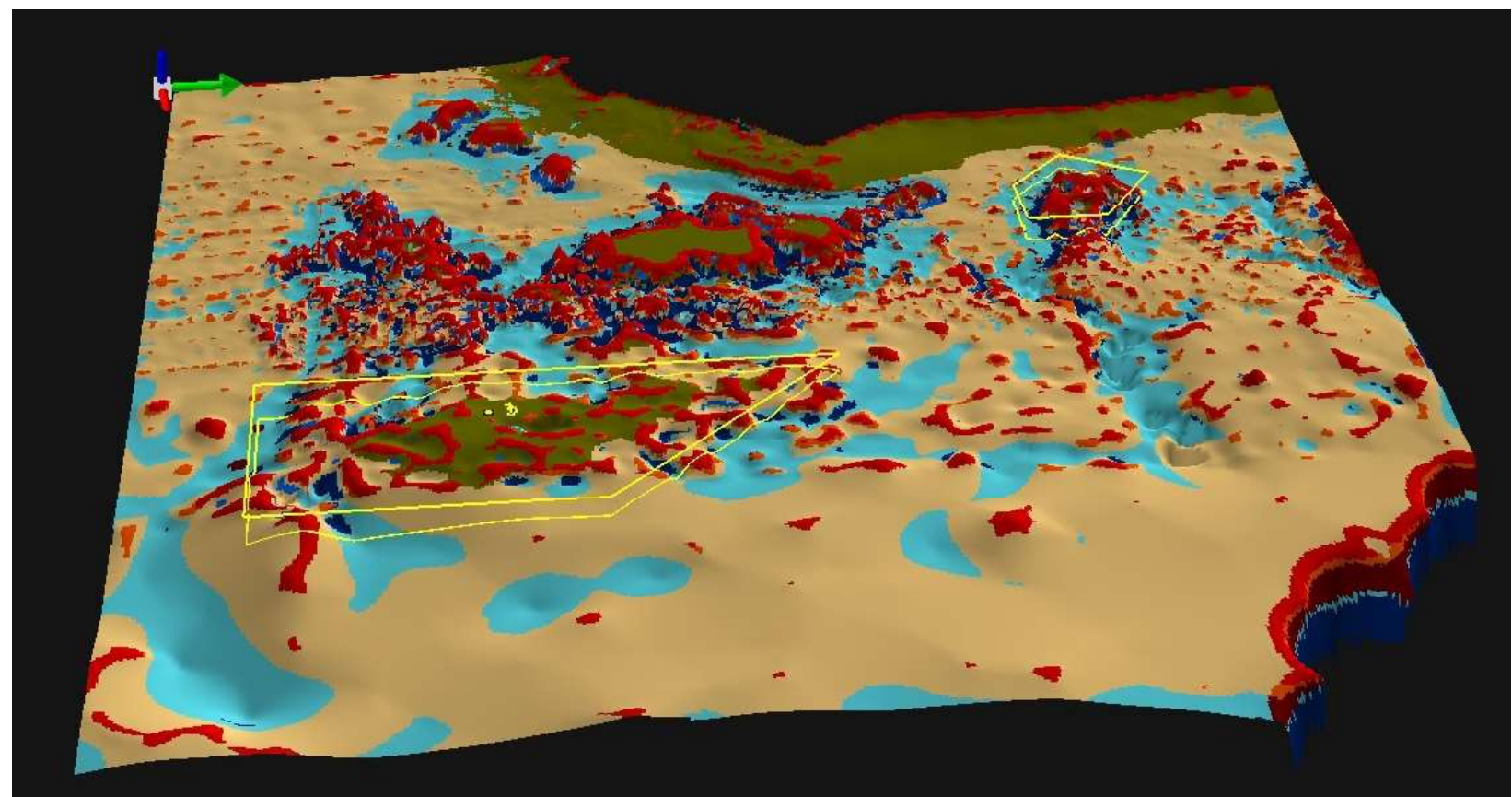

Figura 11 - Estruturas morfológicas de fundo do PARNA Abrolhos e entorno, em perspectiva tridimensional. A porção negra corresponde à área submersa não estudada. Exagero vertical de 100 vezes para efeito de visualização. Vetor verde indica o norte. 


\section{ZONAS MORFOLÓGICAS E PALEODRENAGEM \\ Parque Nacional Marinho de Abrolhos e entorno}

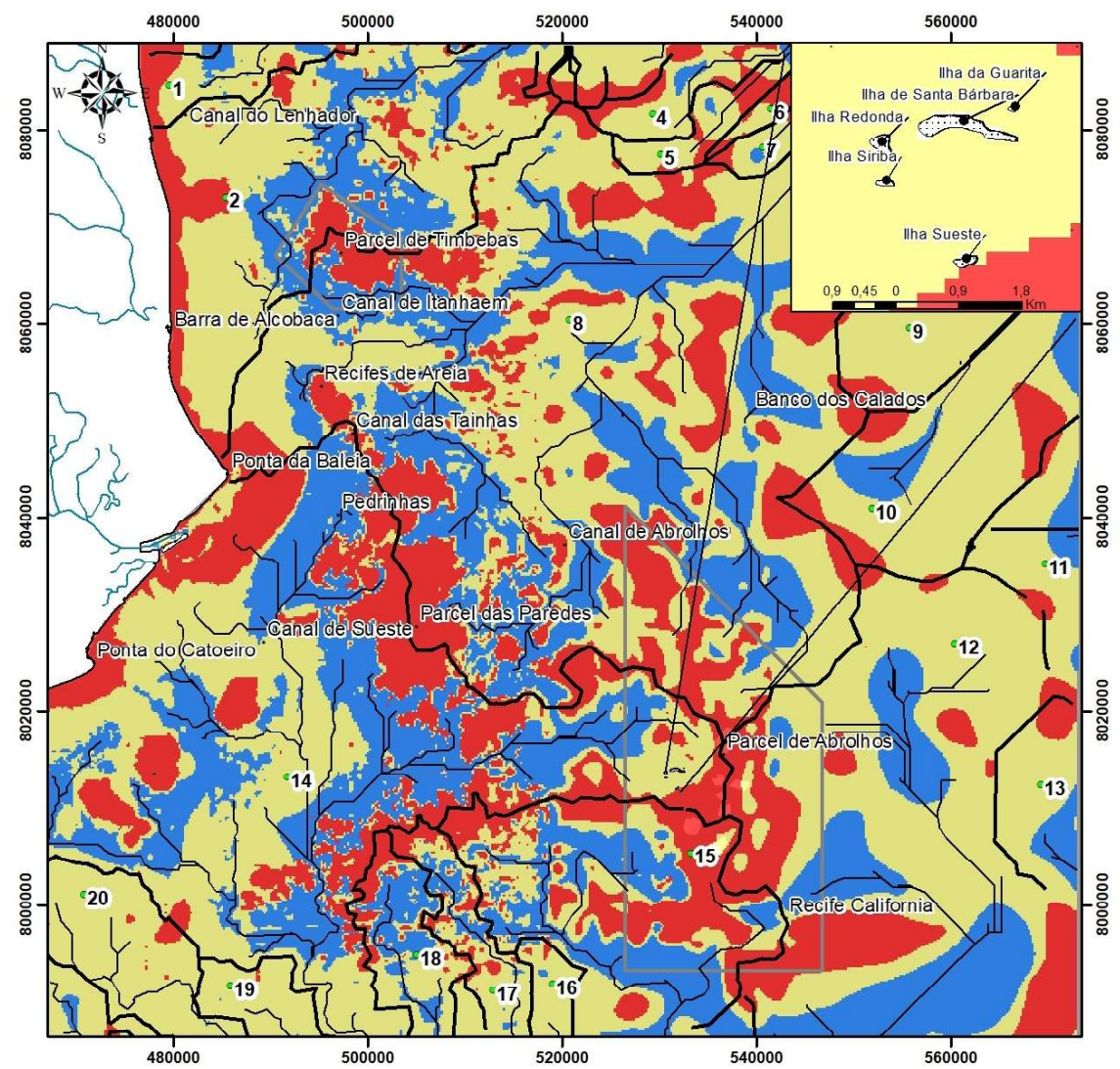

\section{Legenda}

- Paleobacias

- PALEODRENAGEM

PALEOBACIAS

HIDROGRAFIA ATUAL

in:! ILHAS

P.N.M. ABROLHOS

$\square$ TERRA EMERSA

\section{ZONAS}

Cristas

Depressões

Planícies

Vertentes

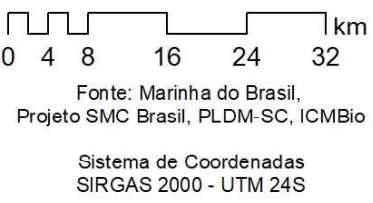

Figura 12 - Paleodrenagem e limites de paleobacias hidrográficas sobre zonas morfológicas de fundo para o PARNA Abrolhos e entorno.

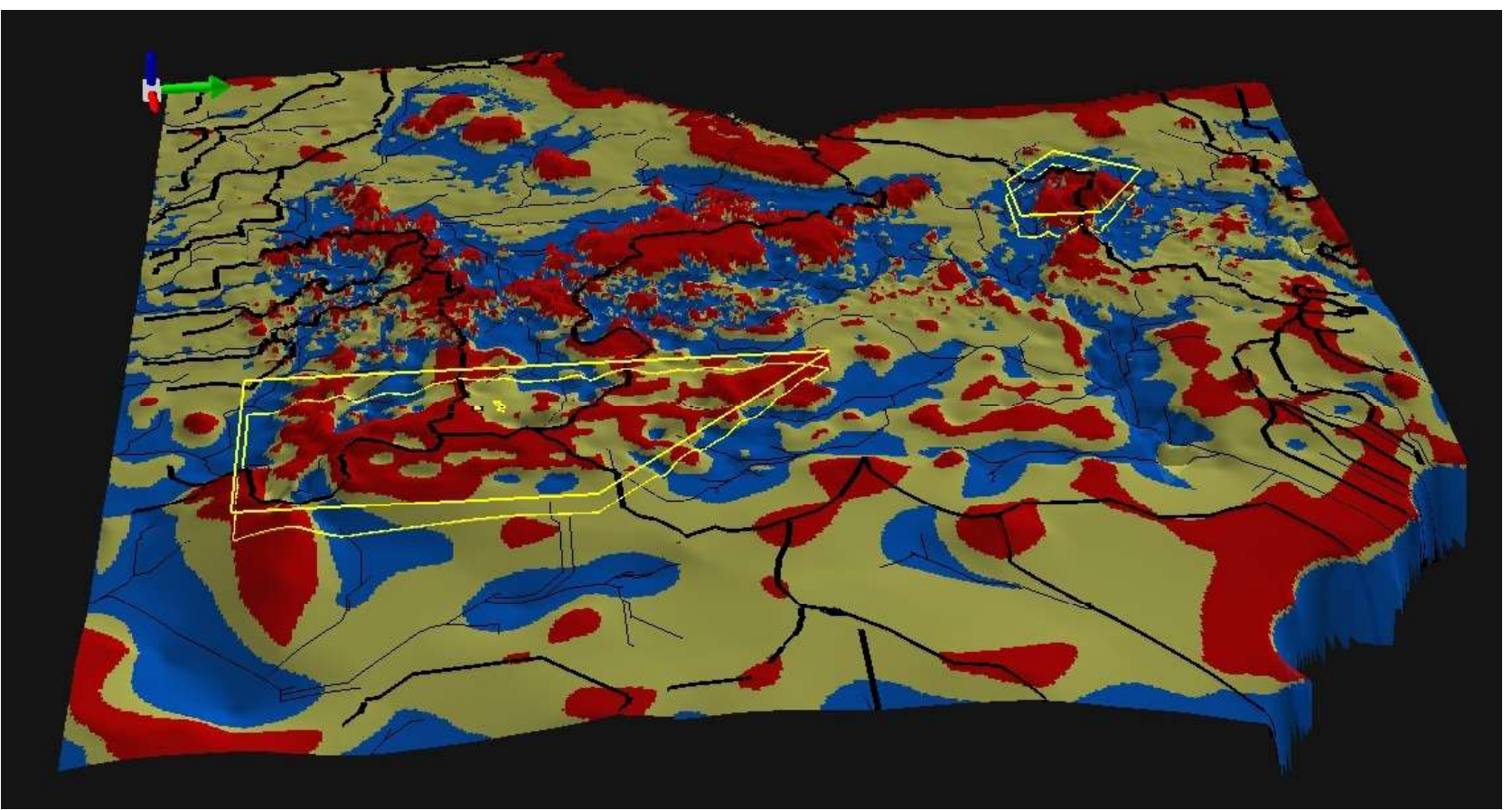

Figura 13 - Paleodrenagem e limites de paleobacias hidrográficas sobre zonas morfológicas de fundo para o PARNA Abrolhos e entorno, em perspectiva tridimensional. A porção negra corresponde à área submersa não estudada. Exagero vertical de 100 vezes para efeito de visualização. Vetor verde indica o norte. 
O mapeamento das estruturas morfológicas (figura 14 e 15) realizado a partir da batimetria (figura 4) apresenta para o interior da REBIOMAR uma grande diversidade de classes, demonstrando um alto grau de complexidade geomorfológica para esta UC. Dentre os elementos que compõem sua geodiversidade se destaca o canal entre as Ilhas Deserta e do Arvoredo (CHLUDINSKI, 2002; IBAMA et al., 2003), acima mencionado, associado a depressões que podem exercer influência sobre a hidrodinâmica local(PEREIRA; SCHETTINI; OMACHI, 2009), com repercussão sobre as características ambientais, em particular a produtividade primária.

Chama a atenção também uma sucessão de feições das classes crista estreita e crista local em planície partindo da Ilha do Macuco (Bombinhas), em direção à Ilha das Gales, passando pela Pedra Noceti, Ilha Deserta, Ilha do Arvoredo (com o canal anteriormente mencionado entre as duas últimas), ponta Oeste da Ilha do Arvoredo e Calhaus de São Pedro (figura 9), que poderia proporcionar algum tipo de conectividade ou barreira biogeográfica na área.

A partir do modelo de reconstrução da paleodrenagem da área da REBIOMAR Arvoredo e seu entorno (figuras 16 e 17), pode-se sugerir localmente a existência de três principais bacias hidrográficas em período de regressão marinha e consequente exposição dessa plataforma. A sudeste da área, o canal entre as atuais Ilhas do Arvoredo e Deserta, onde atualmente se encontra uma das duas Zonas Intangíveis da UC (em função das características ímpares do fundo local), apresenta o que parece ser uma cabeceira de drenagem incisiva na paleopaisagem cuja formação atual, com seixos e rochas soltas arredondadas no leito marinho(IBAMA et al., 2003) seria uma combinação entre rochas roladas por movimentos de massa em condições subaéreas, retrabalhadas pela alta hidrodinâmica local já em condições marinhas.

Já no setor central, as depressões e os pequenos fragmentos de canais em frente à Baía de Tijucas, cujo talvegue segue para NE em direção à Ilha das Galés, assim como o canal entre as Ilhas do Arvoredo e Galés, sugerem um eventual determinismo estrutural das antigas drenagens, cuja herança influenciaria a atual circulação das águas marinhas, conforme anteriormente sugerido por CHLUDINSKY; BONETTI, (2002). A Ilha Deserta aparece como um delimitador das paleomicrobacias, assim como, conjuntamente, a Ilha das Galés e a Pedra Noceti, na bacia identificada mais ao norte, tendo essa paleodrenagem associada ao atual Rio Tijucas sido direcionada para uma paleobacia estabelecida entre as feições citadas.

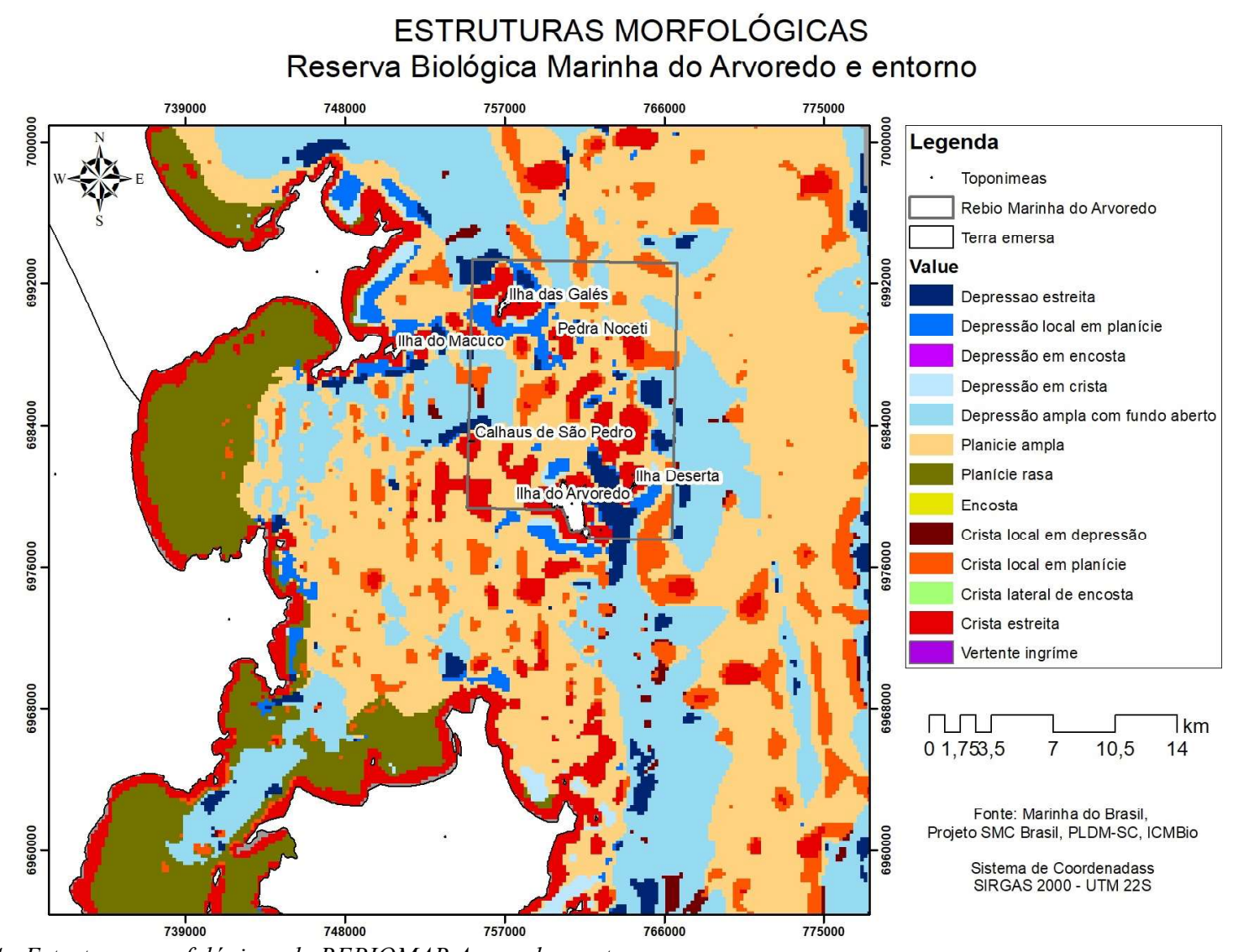

Figura 14 - Estruturas morfológicas da REBIOMAR Arvoredo e entorno. 


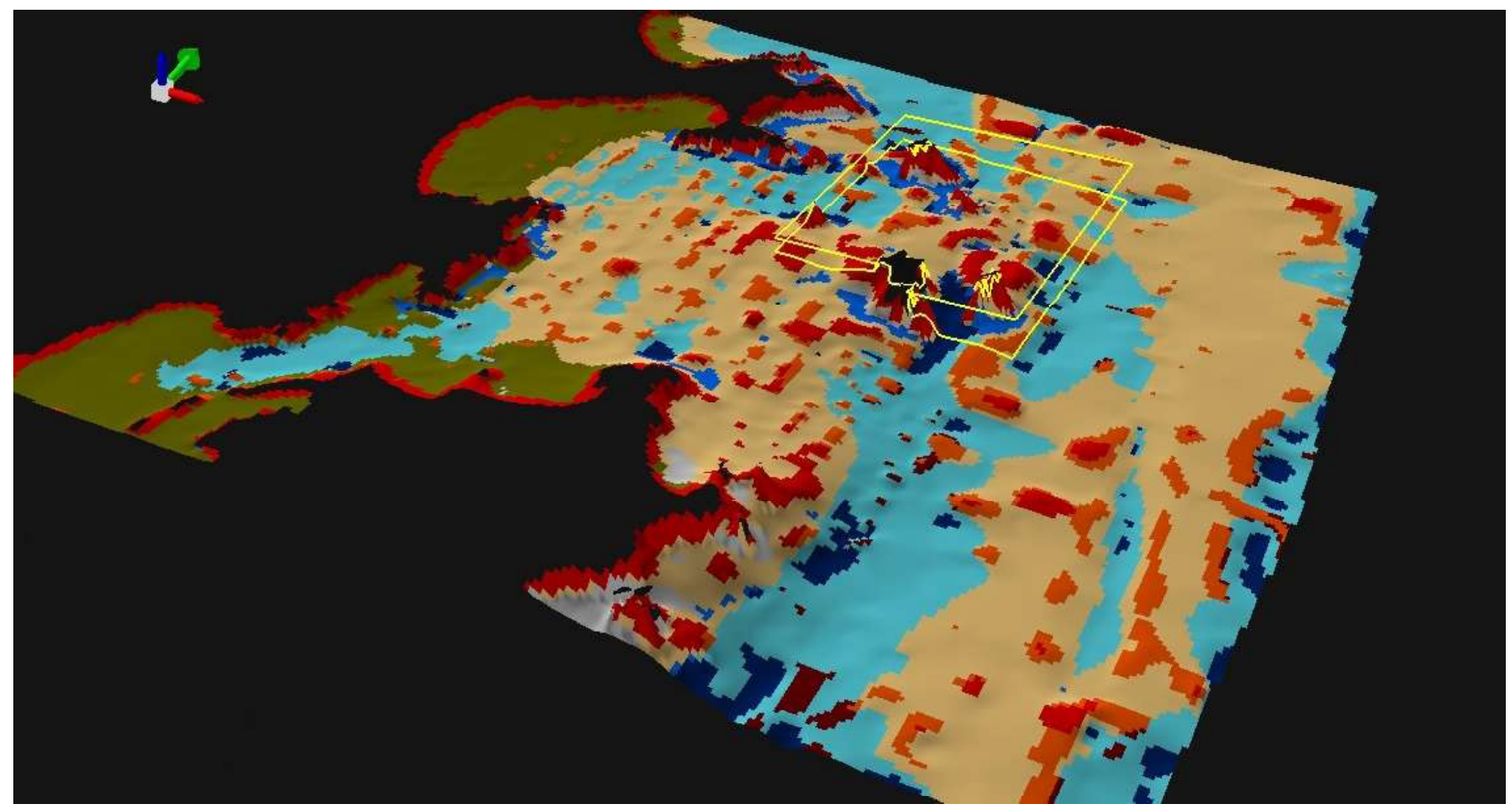

Figura 15 - Estruturas morfológicas da REBIOMAR Arvoredo e entorno, em perspectiva tridimensional. A porção negra corresponde à área submersa não estudada. Exagero vertical de 50 vezes para efeito de visualização. Vetor verde indica o norte.

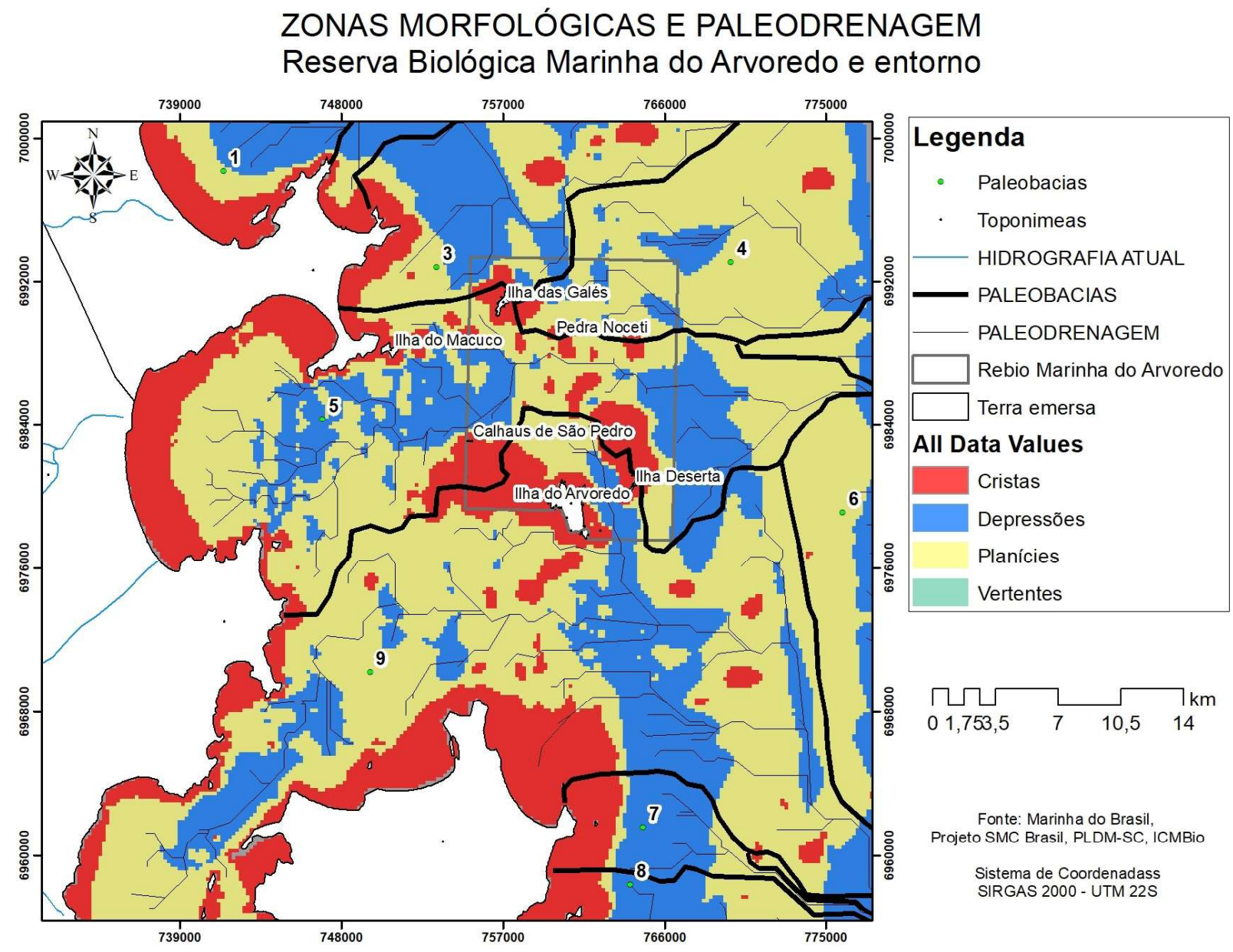

Figura 16 - Paleodrenagem e limites de paleobacias hidrográficas sobre zonas morfológicas de fundo para a REBIOMAR Arvoredo e entorno. 


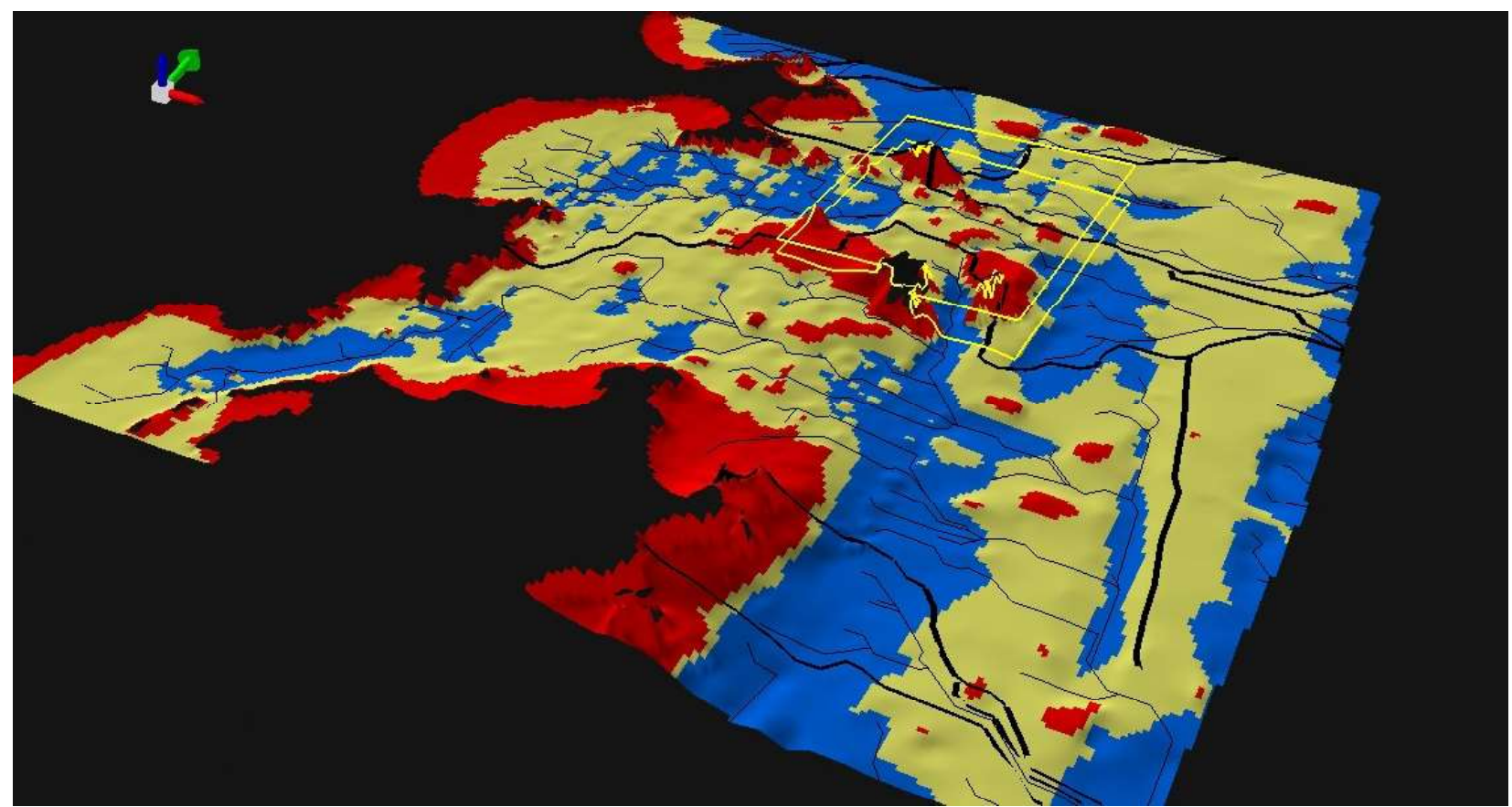

Figura 17 - Paleodrenagem e limites de paleobacias hidrográficas sobre zonas morfológicas de fundo para a REBIOMAR Arvoredo e entorno. A porção negra corresponde à área submersa não estudada. Exagero vertical de 50 vezes para efeito de visualização. Vetor verde indica o norte.

\section{Conclusões}

Várias pesquisas já propuseram a caracterização da geomorfologia submarina da plataforma continental e fundos oceânicos com base na análise da batimetria local, sendo consagrado esse tipo de abordagem. No Brasil, TORRES; JECK; TAVARES, (2003) por exemplo, caracterizaram o Cone do Amazonas através da análise da variação da declividade e da confecção de isóbatas com espaçamento uniforme. Mais recentemente, MOTOKI; MOTOKI; MELO, (2012) descreveram quantitativamente a morfologia da Cadeia Vitória-Trindade a partir da elaboração de mapas topográficos utilizando técnicas analíticas que permitiram o preenchimento digital de vales e drenagens e a remoção de picos e cristas, ampliando assim a capacidade interpretativa do leitor. Este último trabalho foi além da representação visual do relevo e incorporou técnicas de análise espacial em SIG para melhor representar as formas locais. A presente pesquisa igualmente buscou explorar a potencialidade do geoprocessamento na caracterização do relevo submarino, tendo aplicado um procedimento analítico que considera distintos descritores morfológicos para a determinação de zonas e estruturas de relevo e o provável traçado das redes de drenagem pretéritas.
O uso conjunto do BTM, originalmente concebido para aplicação em águas mais profundas e a partir de dados batimétricos de alta resolução, associado à técnica de definição de paleobacias e paleodrenagens, permitiu uma melhor compreensão, em escala espacial média ou regional (equivalente a aproximadamente 1:100.000), do fundo marinho das Unidades de Conservação selecionadas. Dados e informações como os que foram obtidos são de grande potencial para auxiliar no desenvolvimento de novas pesquisas, no planejamento ambiental marinho em diferentes escalas e no manejo dessas UCs.

Os resultados permitem concluir que essas Unidades de Conservação foram criadas em áreas que apresentam alta complexidade morfológica do fundo marinho, o que poderia estar, em certo grau, associado aos elevados índices de biodiversidade encontrados nesses locais. Permitem, ainda, caracterizar parte da geodiversidade do fundo dessas áreas protegidas, algo pouco explorado na criação e no manejo de Unidade de Conservação marinhas.

Parte da morfologia atual do assoalho dessas UCs está diretamente ligada a processos hidrológicos que atuaram em fases de exposição subaérea da plataforma interna, mesmo tendo-se em conta o caráter 
destrutivo das transgressões marinhas que ocorreram posteriormente. Detecta-se, atualmente, uma morfologia residual das transformações ocasionadas pela última transgressão e pela atual dinâmica marinha. Tal característica se mostrou menos evidente em Abrolhos, por provável influência do crescimento recifal, que acompanhou a variação do nível do mar e pode ter induzido padrões estruturais consolidados em curta escala temporal. Pode-se, assim, argumentar que o traçado de paleodrenagens apresenta limitações em plataformas de composição carbonática. A presença marcante do embasamento granítico no Arvoredo, e vulcânico em Fernando de Noronha, condicionou um processo evolutivo diferenciado, que favoreceu incisões mais expressivas e permitiu o estabelecimento de feições mais perenes.

Novas pesquisas alimentadas por dados batimétricos de maior resolução espacial, assim como imageamento de feições de fundo com sonares de varredura lateral e veículos operados remotamente deverão ser realizadas a fim de refinar o mapeamento das morfologias de fundo desses locais, gerando uma nova escala de análise para a identificação de padrões espaciais e relações ecológicas ainda desconhecidas. A definição das classes de estrutura de feições morfológicas de fundo precisa igualmente de um maior refinamento para garantir a representatividade das formas marinhas identificadas. Deve-se considerar a revisão da nomenclatura adotada para as feições reconhecidas, além da inclusão de novas feições que possam ser particularizadas em função de suas características de profundidade e declividade, ou exclusão de outras que se demonstrarem pouco relevantes.

Para o prosseguimento desta investigação, estudos em conjunto com a ecologia e a biologia se fazem necessários para a identificação da representatividade das classes morfológicas de fundo para a organização ecológica local, assim como estudos de hidrodinâmica que possam melhor explicar a organização espacial das formas encontradas. Tal integração permitirá o reconhecimento do nível de organização ecológica que essa escala espacial, relacionada aos processos abióticos, pode representar. Um avanço no conhecimento dessas relações irá otimizar o planejamento sistemático da gestão ambiental marinha de Unidades de Conservação Marinha, aumentando sua eficiência e eficácia, através do emprego dessas feições morfológicas como substitutos (proxy) de sistemas biológicos, em uma primeira aproximação, para a definição das áreas prioritária para a conservação e criação de novas UCs ou corredores ecológicos.

\section{Referências Bibliográficas}

ABREU, J. G. N. De. . Contribuição à Sedimentologia da Plataforama Continental Interna de Santa Catarina entre a Foz dos rios Tijucas e Itapocu. Dissertação de Mestrado. Intituto de Geociencias - Rio de Janeiro: Universidade Federal Fluminense, 1998. p. 67.

ABREU, J. G. N. De. . Sedimentologia, sismoestratigrafia e evolução da plataforma continental interna na área sob influência dos rios Itajaí-Açú e Camboriú, litoral CentroNorte de SC. Tese de Doutorado. Programa de Pós-Graduação em Geociências Porto Alegre: Universidade Federal do Rio Grande do Sul, 2010. p. 140.

ABREU, J. G. N. De; CALliari, L. J. . Paleocanais na plataforma continental interna do Rio Grande do Sul: evidências de uma drenagem fluvial pretérita. Revista Brasileira de Geofisica, v. 23, p. 123-132, 2005.

AL-HAMDANI, Z. K.; REKER, J.; LETH, J. O.; REIJONEN, A.; KOTILAINEN, A. T.; DINESEN, G. E. . Development of Marine Landscape Maps for the Baltic Sea and Kattegat using geophisical and hydrigraphical parameters. Geological Survey of Denmark and Greenland Bulletin (BALANCE Project), v. 13 , p. 5,2007

ALMEIDA, F. F. M. De. . Ilhas oceânicas brasileiras e suas relações com a tectônica atlântica. Terrce Didatica, v. 2, n. 1, p. 3-18, 2006.

ALVES, R. J. V.; CASTRO, J. W. de A. . Ilhas oceânicas brasileiras: da pesquisa ao manejo. [s.1.] MMA/SFP, 2006. p. 298.

ANDRADE, A. C. S.; DOMINGUEZ, J. M. L.; MARTIN, L.; BITTENCOURT, A. C. S. P. . Quaternary evolution of the Caravelas strandplain - Southern Bahia State - Brazil. Anais da Academia Brasileira de Ciências, v. 75, p. 357-382, 2003.

ANGULO, R. J.; LESSA, G. C.; SOUZA, M. C. De. . A critical review of mid- to late-Holocene sea-level fluctuations on the eastern Brazilian coastline. Quaternary Science Reviews, v. 25, n. 5-6, p. 486-506, 2006.

ARTUSI, L.; FIGUEIREDO JR., A. G. De. . Sismografia rasa da plataforma continental de Cabo Frio - Araruama - RJ. Revista Brasileira de Geofisica, v. 25, p. 7-16, 2007.

BOSTRÖM, C.; PITTMAN, S. J.; SIMENSTAD, C.; KNEIB, 
R. . Seascape ecology of coastal biogenic habitats: advances, gaps, and challenges. Marine Ecology Progress Series, v. 427, p. 191-217, 2011.

BRASIL. . Programa REVIZEE: Avaliação do potencial sustentável de recursos vivos na Zona econômica Exclusiva: Relatório Executivo. 1. ed. Brasilia: MMA - Secretaria de Qualidade Ambiental, 2006. v. 1p. 280.

BUHL-MORTENSEN, P.; DOLAN, M.; BUHL-MORTENSEN, L. . Prediction of benthic biotopes on a Norwegian offshore bank using a combination of multivariate analisys and GIS classification. ICES Journal of Marine Science, v. 1, n. 66, p. 2026-2032, 2009.

CAMPOS, A. V. . Caracterização morfológica e sedimentar do substrato das baías Norte e Sul (SC) com base em técnicas de análise espacial. Dissertação de Mestrado. Departamento de Geociências. Florianópolis: Universidade Federal de Santa Catarina, 2011. p. 95.

CHLUDINSKI, A. P. . Integração de dados oceanográficos e de sensoriamento remoto na análise espacial de águas costeiras visando a setorização da Reserva Biológica Marinha do Arvoredo e Baía de Tijucas, SC. Dissertação de Mestrado. Departamento de Geociências. Florianópolis: Universidade Federal de Santa Catarina - UFSC, 2002. p. 147.

CHLUDINSKI, A. P.; BONETTI, J. . Aplicação de um Modelo Digital de Terreno na Caracterização do relevo submerso da Reserva Biológica Marinha do Arvoredo e Baía de Tijucas SC. Gerenciamento Costeiro Integrado, v. 1, n. 2, p. 13-14, 2002.

CONNOR, D. W.; GILlilAND, P. .; GOLDING, N.; ROBINSON, P.; TODD, D.; VERLING, E. . UKSeaMap : the mapping of seabed and water column features of UK seas. . Peterborough: Joint Nature Conservation Committee, 2006. p. 107.

CONTI, L. A.; FURTADO, V. V. . Topographic registers of paleo-valleys on the southeastern brazilian continental shelf. Brazilian Journal of Oceanography, v. 57, n. 2, p. 113-121, 2009.

COOPER, J. A. G.; GREEN, A. N.; MEIRELES, R. P.; KLEIN, A. H. F.; SOUZA, J.; TOLDO, E. E. . Sandy barrier overstepping and preservation linked to rapid sea level rise and geological setting. Marine Geology, v. 382, p. 80-91, 2016.

EKAU, W.; KNOPPERS, B. . Sedimentation processes and prductivity in the continental shelf waters off east and northeast Brazil Joint Oceanographic Projects (JOPS-II). Cruise report and first results. . [s.1.] Bundesministerium fuer Bildung, Wissenschaft, Forschung und Technologie, Bonn (Germany), 1996. p. 152.
FAGHERAZZI, S.; HOWARD, A. D.; NIEDORODA, A. W.; WIBERG, P. L. . Controls on the degree of fluvial incision of continental shelves. Computers \& Geosciences, v. 34, n. 10, p. 1381-1393, 2008

FERREIRA, T. S. . Análise estrutural da deformação Cenozóica na Bacia de Cumuruxatiba (BA). Natal, RN: Universidade Federal do Rio Grande do Norte, 2010. p. 127.

FURTADO, V. V.; BONETTI FILHO, J.; CONTI, L. A. . Paleo river valley morphology and sea level changes on the southeastern Brazilian Continental Shelf. Anais da Academia Brasileira de Ciências, v. v.68, n. Supl. 1, p. 163-169, 1996.

HAMDI, A.; POPULUS, J.; PIEL, S. . Marine landscape maps: methodology and potential use. Anais: CoastGIS 07, the 8th International Symposium on GIS and Computer Mapping for Coastal Zone Management - GIS Technologies and spatial data infrastructures for the integrated management of coastal zones and the marine environment. Santander - Spain: IFREMER, 2007

HARRIS, P. T. . From seafloor geomorphology to predictive habitat mapping: progress in applications of biophysical data to ocean management. Anais: MAREANO - International workshop on seabed mapping methods and technology. Trondheim, Norway: MAREANO, 2012

IAMPIETRO, P. J.; KVITEK, R. G.; MORRIS, E. . Recent Advances in Automated Genus-specific Marine Habitat Mapping Enabled by High-resolution Multibeam Bathymetry. Marine Technology Society Journal, v. 39, n. 3, p. 83-93, 2005.

IAMPIETRO, P. J.; YOUNG, M. A.; KVITEK, R. G. . Multivariate Prediction of Rockfish Habitat Suitability in Cordell Bank National Marine Sanctuary and Del Monte Shalebeds, California, USA. Marine Geodesy, v. 31, n. 4, p. 359-371, 2008.

IBAMA. . Plano de Manejo do Parque Nacional Marinho de Abrolhos. Brasilia, Brasil, 1991.

IBAMA. . Roteiro Metodológico de Planejamento: Parque Nacional, Reserva Biológica, Estação Ecológica. 1. ed. Brasília: MMA, 2002. p. 136.

IBAMA. . Plano de Manejo da APA de Fernando de Noronha e APA de São Pedro e São Paulo. Brasilia, 2005.

I B A M A ; S O C I O A M B IENTAL; APRENDER; SOCIOAMBIENTAL. Plano de Manejo da Reserva Biológica Marinha do Arvoredo. (DIREC, Ed.)Brasilia, 2003.

IBGE; NUNES, B. de A.; RIBEIRO, M. inês de C.; ALMEIDA, V. J.; FILHO, T. N. . Manual Técnico de Geomorfologia. Rio 
de Janeiro: IBGE, 1995. v. 5p. 50.

ICMBIO. . Proposição de Unidades de Conservação na Região dos Abrolhos - Documento Base. . Brasilia, D.F.: Instituto Chico Mendes de Conservação da Biodiversidade - Ministério do Meio Ambiente - ICMBio, 2012. p. 27.

JENNESS, J. S. . Topographic Position Index (TPI) v. 1.2. Documentation. Jenness Enterprises, , 2006.

DOMingueZ J. M. L. . The Coastal Zone of Brazil : an Overview. Journal of Coastal Resarch, n. 39, p. 16-20, 2004.

KENDALL, M. S.; BAUER, L. J.; JEFFREY, C. F. G. . Influence of hard bottom morphology on fish assemblages of the continental shelf off Georgia, Southeastern USA. Bulletin of Marine Science, v. 84, n. 3, p. 265-286, 2009.

KENDALL, M. S.; MILlER, T. J.; PITTMAN, S. J. . Patterns of scale-dependency and the influence of map resolution on the seascape ecology of reef fish. Marine Ecology Progress Series, v. 427, p. 259-274, 2011.

KNOPPERS, B.; EKAU, W.; FIGUEIREDO, A. G. . The coast and shelf of east and northeast Brazil and material transport. Geo-Marine Letters, v. 19, n. 3, p. 171-178, 1999.

KRACKER, L.; KENDALL, M.; MCFALL, G. . Benthic Features as a Determinant for Fish Biomass in Gray's Reef National Marine Sanctuary. Marine Geodesy, v. 31, n. 4, p. 267-280, 2008.

LEÃO, Z. M. A. N. . Morphology, geology and development history of the southernmost coral reefs of western Atlantic, Abrolhos Bank, Brazil. Tese de Doutorado. Miami: University of Miami, 1982. p. 218.

LEÃO, Z. M. A. N. . Abrolhos, BA: O complexo recifal mais extenso do Atlântico Sul. em: SCHOBBENHAUS,C. CAMPOS, D. A. et al. (Eds.). . Sítios Geológicos e Paleontológicos do Brasil. 1. ed. [s.1: s.n.]. p. 345-359. 2002

LEÃO, Z. M. A. N.; KIKUCHI, R. K. P. . A relic coral fauna threatened by global changes and human activities, Eastern Brazil. Marine Pollution Bulletin, v. 51, n. 5-7, p. 599-611, 2005.

LEIPE, T.; KNOPPERS, B.; MARONE, E.; CAMARGO, R. Suspended matter transport in coral reef waters of the Abrolhos Bank, Brazil. Geo-Marine Letters, v. 19, n. 3, p. 186-195, 1999.

LUNDBLAD, E. R. . The Development and Application of Benthic Classifications for Coral Reef Ecosystems Below 30 m Depth using Multibeam Bathymetry: Tutuila, American
Samoa. Dissertação de Mestrado. Oregon: Oregon State University, 2004. p. 137.

LUNDBLAD, E. R.; WRIGHT, D. J.; MILLER, J.; LARKIN, E. M.; RINEHART, R. W.; NAAR, D. F.; DONAHUE, B. T.; ANDERSON, S. M.; BATTISTA, T. . A Benthic Terrain Classification Scheme for American Samoa. Marine Geodesy, v. 29, n. 2, p. 89-111, 2006.

MAHIQUES, M. M. De; SOUSA, S. H. de M. e; FURTADO, V. V.; TESSLER, M. G.; TOLEDO, F. A. de L.; BURONE, L.; FIGUEIRA, R. C. L.; KLEIN, D. A.; MARTINS, C. C.; ALVES, D. P. V. . The Southern Brazilian shelf: general characteristics, quaternary evolution and sediment distribution. Brazilian Journal of Oceanography, v. 58, p. 25-34, 2010.

MARCHIORO, G. B.; CIRANO, M.; SILVEIRA, I. Da; CAMPOS, R. de O.; COELHO, H. A.; NUNES, M. A. . Subsídios para a delimitação das zonas de amortecimento do parque nacional marinho dos Abrolhos e reserva extrativista marinha do Corumbau por meio da avaliação de impactos potenciais de derramamentos de óleo - Conservation International Brasil. . Caravelas, Bahia: [s.n.]. p. 142.

MAROTTA, L.; AGUZZI, J. . Coastal and Marine Landscape Ecology Based on Marine Geospatial Data Infrastructure for Analysis of Marine Resources and Fishing Effort. Instrumental Viewpoint 8, 2009.

MMA. . Áreas Prioritárias para a Conservação, Uso Sustentável e Repartição de Benefícios da Biodiversidade Brasileira: Atualização - Portaria MMAn ${ }^{\circ} 9$, de 23 de janeiro de 2007. [s.1: s.n.].

MMA. . Macrodiagnóstico da Zona Costeira e Marinha do Brasil. Brasília: IBAMA, 2008. v. 1p. 242.

MOTOKI, A.; MOTOKI, K. F.; MELO, D. P. De. . Caracterização da morfologia submarina da cadeia Vitória-rTrindade e áreas adjacentes, ES, com base na batimetria predita do TOPO VERSÃO 14.1. Revista Brasileira de Geomorfologia, v. 13, n. 2, 2012.

NOAA. . Benthic Terrain Modeler: Introducion to Benthic Terrain Modelling. (N.-C. S. Center, Ed.)OregonNOAA Oregon State University, , 2010.

PAQUETTE, M.-L.; BONETTI, C.; BITENCOURT, V.; BONETTI, J. . Spatial patterns of benthic foraminifera as a support to the oceanographic characterisation of Arvoredo biological marine reserve (South Atlantic, Brazil). Marine environmental research, v. 114, p. 40-50, 2016.

PEREIRA, M. D.; SCHETTINI, C. A. F.; OMACHI, C. Y. . 
Caracterização de feições oceanográficas na plataforma de Santa Catarina através de imagens orbitais. Revista Brasileira de Geofisica, v. 27, p. 81-93, 2009.

PIRES, D. O.; CASTRO, C. B.; RATTO, C. C. . Reef coral reproduction in the Abrolhos Reef Complex, Brazil: the endemic genus Mussismilia. Marine Biology, v. 135, n. 3, p. 463-471, 1999.

RINEHART, R. W.; WRIGHT, D. J.; LUNDBLAD, E. R.; LARKIN, E. M.; CARY-KOTHERA, L.; MURPHY, J.; CARYCOTERA, L. . ArcGis 8.X Benthic Terrain Modeler: Analysis in American Samoa. (E. U. Conference, Ed.)Anais: ESRI User Conference. San Diego, CA: 2004

ROFF, J. C.; TAYLOR, M. E. . National frameworks for marine conservation: a hierarchical geophysical approach. Aquatic Conservation: Marine and Freshwater Ecosystems, v. 10, n. 3, p. 209-223, 2000.

RUDORFF, F. de M.; KAMPEL, M.; SUMIDA, P. Y. G. - Processamento digital de imagem IKONOS para o mapeamento de chapeirões no Parcel dos Abrolhos, BA. Anais: XIV Simposio Brasileiro de Sensoriamento Remoto. Natal, Brasil: INPE, 2009

SANTOS, M. I. F.; ABREU, J. G. N. De; SOUZA, J. A. G.; REUSS-STRENZEL, G. . Caracterização preliminar dos sedimentos nos entornos da area submersa da Reserva Biológica Marinha do Arvoredo, SC, Brasil. (IO-USP, Ed.) Anais: III Simpósio sobre Oceanografia. IO-USP: IO-USP, 1996

SERAFINI, T. Z.; FRANÇA, G. B. De; ANDRIGUETO-FILHO, J. M. . Ilhas oceânicas brasileiras: biodiversidade conhecida e sua relação com o histórico de uso e ocupação humana. Revista da Gestão Costeira Integrada, v. 10, p. 281-301, 2010.

SHEPARD, F. P. . Submarine Geology. 3rd. ed. [s.1.] Joanna Cotler Books, 1973. p. 517.

SIBSON, R. . A brief description of Natural Neighbour Interpolation. em: BARNETT, V. (Ed.). . Interpreting Multivariate Data (Probability and Mathematical Statistics). New York: Wiley and Sons, . p. 21-36. 1981

Suguio, K.; MARTIN, L.; BTtenCOURT, A. C. S. P.; DOMINGUEZ, J. M. L.; FLEXOR, J.-M.; AZEVEDO, A. E. G. De. . Flutuações do nível do mar durante o quaternário superior ao longo do litoral brasileiro e suas implicações na sedimentação costeira. Revista Brasileira de Geociências, v. 15, n. 4, p. 273-286, 1985.
SuguiO, K.; TESSler, M. G. . Planícies de cordões litorâneos quaternários do Brasil: origem e nomenclatura. em: Restingas: origem, estrutura e processos. Rio de Janeiro: UFF, . p. 15-25. 1984

TOMAZZOLI, E.; LIMA, E. F. De. . Litotipos da Ilha do Arvoredo (SC): Considerações petrogenéticas. Anais: XL II Congresso Brasileiro de Geologia. Araxá - MG: Sociedade Brasileira de Geologia, 2004

TORRES, L. C.; JECK, I. K.; TAVARES, A. A. L. A. . Configuração Morfológica do Cone do Amazonas a Partir da Integração de Dados Batimétricos. Revista Brasileira de Geomorfologia, v. 4, n. 1, 2003.

VILLWOCK, J. A. . A costa brasileira: geologia e evolução. Notas Técnicas - CECO, n. 7, p. 11, 1994.

WEDDING, L. M.; LEPCZYK, C. A.; PITTMAN, S. J.; FRIEDLANDER, A. M.; JORGENSEN, S. . Quantifying seascape structure: extending terrestrial spatial pattern metrics to the marine realm. Marine Ecology Progress Series, v. 427, p. 219-232, 2011.

WESCHENFELDER, J.; ALIOTTA, S.; BAITELLI, R.; CORREA, I. C. S. . Paleochannels related to late quaternary sea-level changes in Southern Brazil. Brazilian Journal of Oceanography, v. 58, p. 35-44, 2010.

WESCHENFELDER, J.; CORRÊA, I. C. S.; TOLDO JR., E. E.; BAITELLI, R. . Paleocanais como indicativo de eventos regressivos quaternários do nível do mar no Sul do Brasil. Revista Brasileira de Geofísica, v. 26, p. 367-375, 2008.

WRIGHT, D. J.; LUNDBLAD, E. R.; LARKIN, E. M.; RINEHART, R. W.; MURPHY, J.; CARY-KOTHERA, L.; DRAGANOV, K. . Benthic Terrain Modeler. Corvallis, OregonOregon State University, , 2005.

YOUNG, M. A.; IAMPIETRO, P. J. P.; KVITEK, R. G.; GARZA, C. D. . Multivariate bathymetry-derived generalized linear model accurately predicts rockfish distribution on Cordell Bank, California, USA. Marine Ecology Progress Series, v. 415, n. 415, p. 247-261, 2010.

ZEMBRUSKI, S. G. . Geomorfologia da Margem Continental Sul Brasileira e das Bacias Oceânicas Adjacentes. (Série Projeto REMAC. 7, Ed.) Geomorfologia da margem continental brasileira e das áreas oceânicas adjacentes. Rio de Janeiro: PETROBRAS, CENPES, DINTEP, 177 p, 1979. p. 129-177. 